\title{
Iron Oxide Nanoparticles in Mesenchymal Stem Cell Detection and Therapy
}

\author{
Kosha J. Mehta ${ }^{1}$ (1) \\ Accepted: 24 January 2022 / Published online: 1 February 2022 \\ (c) The Author(s) 2022
}

\begin{abstract}
Mesenchymal stem cells (MSCs) exhibit regenerative and reparative properties. However, most MSC-related studies remain to be translated for regular clinical usage, partly due to challenges in pre-transplantation cell labelling and post-transplantation cell tracking. Amidst this, there are growing concerns over the toxicity of commonly used gadolinium-based contrast agents that mediate in-vivo cell detection via MRI. This urges to search for equally effective but less toxic alternatives that would facilitate and enhance MSC detection post-administration and provide therapeutic benefits in-vivo. MSCs labelled with iron oxide nanoparticles (IONPs) have shown promising results in-vitro and in-vivo. Thus, it would be useful to revisit these studies before inventing new labelling approaches. Aiming to inform regenerative medicine and augment clinical applications of IONP-labelled MSCs, this review collates and critically evaluates the utility of IONPs in enhancing MSC detection and therapeutics. It explains the rationale, principle, and advantages of labelling MSCs with IONPs, and describes IONP-induced intracellular alterations and consequent cellular manifestations. By exemplifying clinical pathologies, it examines contextual in-vitro, animal, and clinical studies that used IONP-labelled bone marrow-, umbilical cord-, adipose tissue- and dental pulp-derived MSCs. It compiles and discusses studies involving MSC-labelling of IONPs in combinations with carbohydrates (Venofer, ferumoxytol, dextran, glucosamine), non-carbohydrate polymers [poly(L-lysine), poly(lactide-co-glycolide), poly(L-lactide), polydopamine], elements (ruthenium, selenium, gold, zinc), compounds/stains (silica, polyethylene glycol, fluorophore, rhodamine B, DAPI, Prussian blue), DNA, Fibroblast growth Factor-2 and the drug doxorubicin. Furthermore, IONP-labelling of MSC exosomes is reviewed. Also, limitations of IONP-labelling are addressed and methods of tackling those challenges are suggested.
\end{abstract}

Keywords Mesenchymal stem cells · iron · iron oxide nanoparticles · MSC therapy $\cdot$ MSC detection · Stem cell therapy

\section{Introduction}

Mesenchymal stem cells (MSCs) are present throughout the human body in various tissues. MSCs show niche-dependent multilineage differentiation and secrete therapeutic exosomes and growth factors (paracrine effects) to support various physiological processes. These cells can migrate to sites of injury/inflammation and demonstrate their regenerative and reparative properties. Also, MSCs exhibit tropism towards tumours. Thus, MSCs possess the ability to facilitate both cell-based and cell-free therapeutics and promise targeted therapy [1-4].

Kosha J. Mehta

kosha.mehta@kcl.ac.uk

1 Centre for Education, Faculty of Life Sciences and Medicine, King's College London, London, UK
MSCs are usually extracted from bone marrow, adipose tissue, umbilical cord, and placenta. These cells are easy to isolate, the cells expand in-vitro, retain phenotypic characteristics and differentiation potential in-vitro, and make autologous transplantation feasible [5, 6]. MSCs offer advantages over other transplantable stem cells such as embryonic and induced pluripotent stem cells and are therefore gaining popularity. Allogenic MSC transplantation has been performed on patients with haematological malignancy, cardiomyopathies and graft v/s host disease [6]. Promising results have been obtained in clinical trials that targeted amelioration of knee osteoarthritis [7, 8], multiple sclerosis [9] and spinal cord injury [10], as well as in animal models of myocardial infarction [11-13], multiple sclerosis [14], sensorineural hearing loss [15], and bone defects [16]. Moreover, using MSCs to treat COVID-19 patients has been discussed [17-20]. 


\section{Rationale}

Hitherto, the therapeutic potential of MSCs has been assessed in over a thousand MSC-related clinical trials, as listed on the Clinical Trials Register for EU (https:// www.clinicaltrialsregister.eu/) and ClinicalTrials.gov for USA (http://clinicaltrials.gov/). However, only a few have been translated successfully into regular clinical practice [6]. While this is partly due to the unavailability of sufficient number of MSCs for clinical utility [21] and the risks and side-effects posed by MSCs post transplantation $[22,23]$, this is also due to the issues encountered during pre-administration labelling procedures that subsequently affect MSC detection, homing, and therapeutic potential. Notably, the healing benefit of MSCs is dependent on their ability of homing at target sites [23] where these cells secrete trophic and immunomodulatory molecules [3]. This raises the significance of pre-transplantation labelling procedures to achieve maximum therapeutic efficiency. Moreover, the transplanted MSCs must effectively differentiate at the target site to execute their regenerative function, but MSC differentiation ability in-vivo could be low. For successful homing and differentiation in-vivo, the preadministration approaches require multi-step and complex in-vitro methodology, which is yet to be perfected. These aspects collectively challenge the detection and retention of transplanted MSCs and thereby hamper their frequent clinical usage.

Prior to transplantation, MSCs are often labelled with contrast agents to facilitate subsequent detection and tracking of cells via magnetic resonance imaging (MRI). Although paramagnetic ions involving chromium, manganese, and gadolinium are commonly used as MRI contrast agents, there are growing concerns over their toxicity; particularly, gadolinium-based contrast agents that have been used in pre-clinical models [24]. Also, gadolinium exposure may contribute to nephrogenic systemic fibrosis in patients with reduced kidney function and may cause gadolinium deposition in the brain in patients with normal kidney function [25]. Moreover, most agents distribute systemically and therefore show poor performance in certain clinical applications, for example, gastrointestinal imaging [26].

Thus, it is essential to search for effective but less toxic substitutes that would retain the ability to detect the transplanted MSCs non-invasively, preserve MSC homing and therapeutic potential, and enhance their reparative properties post transplantation.

MSCs can be labelled with iron oxide nanoparticles (IONPs) that act as good MRI contrast agents [27]. The imaging artifact posed by IONPs is much larger than the labelled cell. So, in this context, these are superior to gadolinium-based contrast agents [28]. IONP-labelling of MSCs has been tested in-vitro, and labelled MSCs have been successfully detected by MRI and tested in animal models of disease [29], where the combination of IONPlabelling of MSCs and MRI has shown huge diagnostic and therapeutic potential [30]. Therefore, before reinventing the wheel and exploring new approaches, it would be beneficial to revisit the field and assess IONP's potential in improving MSC detection and homing post-administration. Then, these approaches could be modified to augment MSC therapy for future clinical applications.

Accordingly, this review conglomerates and critically evaluates the usage of IONPs in enhancing MSC detection and therapeutics. By exemplifying several clinical pathologies, it examines MSC-labelling of IONPs in combination with carbohydrates, non-carbohydrate polymers, elements, compounds, stains, DNA, growth factor, and the drug doxorubicin. Limitations are mentioned and putative solutions are suggested.

\section{Fundamentals of Labelling MSCs with IONPs}

The success of any cell therapy is dependent on the migration, engraftment, homing, proliferation, and differentiation of the transplanted stem cells at the target site where these cells exhibit their reparative functions. With regard to MSCs, there is loss of transplanted MSCs in-vivo and there is only little evidence that the MSCs proliferate in-vivo post transplantation [6]. Thus, it is important to longitudinally track the destination and fate of the transplanted MSCs. This not only helps evaluate cell treatment efficacy but also aids in formulating and improvising the time, dosage, and delivery route of cell-transplants.

Post-transplantation cell engraftment can be detected through histological analysis of sacrificed animals or tissues. This is invasive and does not facilitate long-term monitoring of transplanted cells in humans. Thus, non-invasive methods are used, which include the usage of endogenous molecules with intrinsic fluorescence or external fluorescent and non-fluorescent molecules that can be tracked by in-vivo imaging. However, these contrast agents are challenged by low transfection efficiency, photo-bleaching over time, invivo degradation and interference from tissue autofluorescence [27]. Therefore, alternative approaches of MSC labelling are sought that provide reliable real-time cell tracking non-invasively.

MRI is a non-invasive method for cell tracking. It involves exposure of cells and tissues to high magnetic fields, which enables visualisation of the transplanted cells in-vivo. It has varied clinical applications and is more popular than other methods because it offers deep penetration, 3-D imaging, better spatial resolution and soft tissue contrast without 
ionising radiation [26]. It is not possible to directly distinguish between host cells and transplanted cells on a cellular scale using the usual MRI resolution. Therefore, cells to be transplanted are labelled with MRI-visible particles i.e., contrast agents like IONPs to increase the resolution and contrast of the image so that areas of interest can be easily identified.

MRI has been used for detecting hepatic iron in transfusion iron-overload [31, 32], where the paramagnetic effect of hemosiderin [water-insoluble, degraded ferritin (iron)] generates local field inhomogeneities such that the regions where iron is present appear darker than other regions in the field. MSC labelling with IONPs is based on this principle. Essentially, entry of IONPs inside the cells increases cellular/tissue iron content (Fig. 1). Upon exposure to a magnetic field, these labelled cells/tissues create and increase localised inhomogeneities in the magnetic field by inducing a negative contrast i.e., a darker area (spots) in regions where iron is accrued. This increases the visual contrast between different tissues and thereby aids in cell visualisation and tracing of transplanted cells in-vivo via MRI. IONPs have been used for clinical imaging for more than two decades [34].

Typical structural and functional characteristics of IONPs have been tabulated (Table 1). Also, some features of IONPlabelling of MSCs have been tabulated (Table 2).

\section{MSC Tropism towards Tumour/Inflammation and Contextual IONP-Induced MSC Alterations}

MSCs exhibit tropism towards tumours [1] and have shown to home into tumours of animal models of cancers; namely, in cancers of liver, lung, breast, colon and brain glioma. This MSC tropism and homing involves chemokines released from tumours that attract and recruit MSCs with corresponding receptors (Fig. 2) [49]. For example, glioma cells release many chemokines and growth factors including stromal cellderived factor-1 (SDF-1), monocyte chemoattractant protein-1 (MCP-1), transforming growth factor-beta (TGF- $\beta$ ), VEGF, IL-8 and neurotrophin-3. These chemokines support MSC tropism for gliomas [50] by pairing with receptors on MSCs (Fig. 2). Examples of cytokine-receptor pairs implicated in MSC tumour tropism are SDF-1 \& C-X-C motif chemokine receptor-4 (CXCR4), VEGF \& VEGFR, MCP-1 \& C-C motif chemokine receptor (CCR2), epidermal growth factor (EGF) \& EGFR, and hepatocyte growth factor (HGF) \& c-Met [51]. These pairs have also been implicated in MSC tropism towards injury/inflammation sites (Fig. 2). However, in the MSCs, expression levels of receptors like CXCR4, CCR1 or c-met can be low. Therefore, several studies have

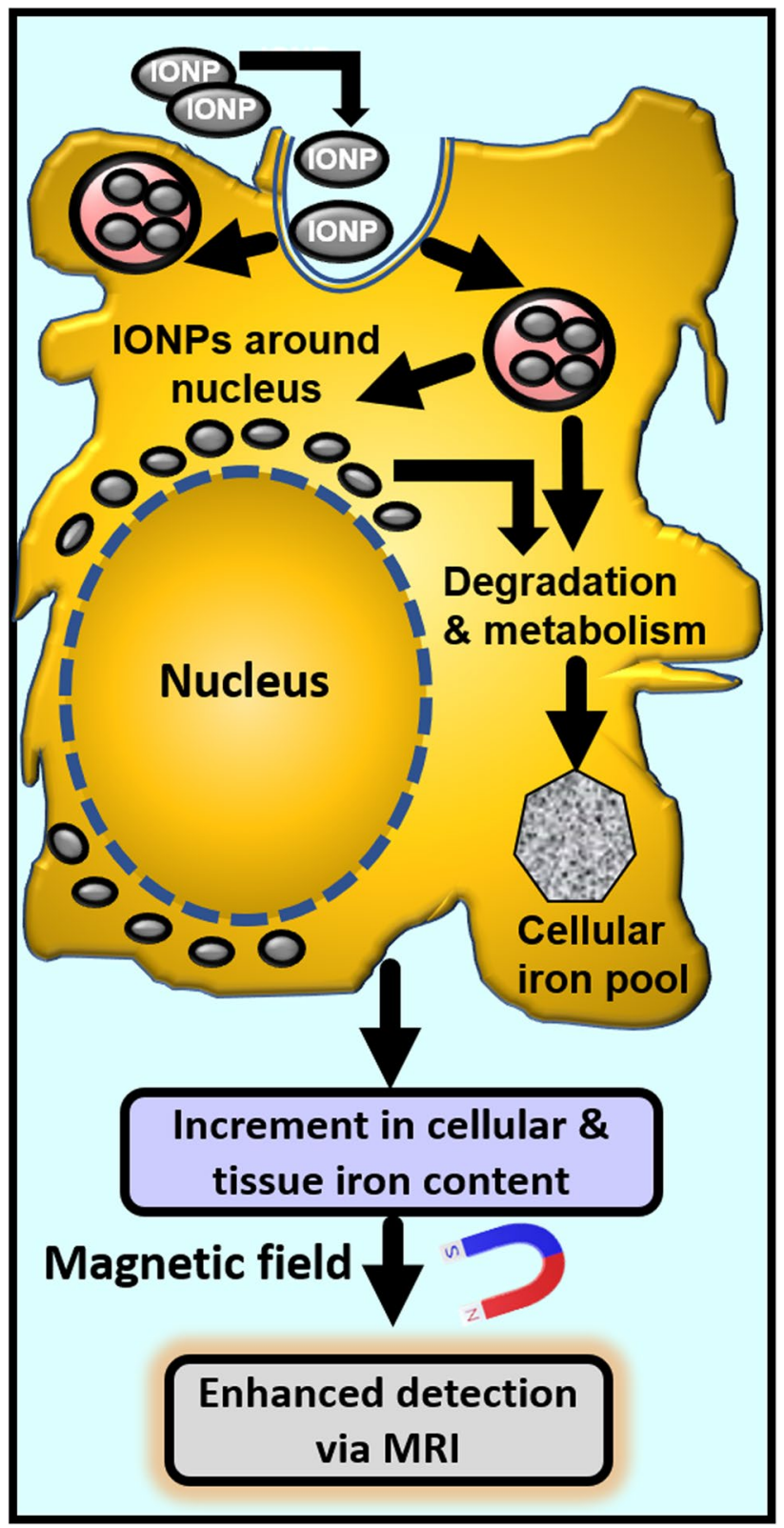

Fig. 1 Iron oxide nanoparticle (IONP) endocytosis and enhanced detection via MRI. IONPs can be taken up into endo/lysosomes by receptor-mediated endocytosis, phagocytosis, or pinocytosis. A clathrin-mediated and actin-dependent endocytosis of IONPs in MSCs has been reported. IONPs localise within lysosomes and around the nucleus. After degradation and metabolism, iron inside these particles is incorporated into the cellular iron pool. Total cellular/tissue iron content is increased, which facilitates detection via MRI [27, 28, 30, 33]

been conducted to improve their expressions in MSCs to enhance MSC migration [2].

Injury-induced release of cytokines e.g. SDF-1 can upregulate CXCR4 on MSC surfaces and this can promote chemotaxis i.e. migration of regenerative cells and homing of MSCs into target sites [5, 52, 53]. Likewise, 
Table 1 Selected structural and functional characteristics of IONPs

\begin{tabular}{|c|c|}
\hline Parameter & Characteristics of IONPs \\
\hline Composition & $\begin{array}{l}\text { IONPs are composed of a bioreactive iron oxide core (either magnetite } \mathrm{Fe}_{3} \mathrm{O}_{4} \text { or maghemite } \gamma-\mathrm{Fe}_{2} \mathrm{O}_{3} \text { ) sur- } \\
\text { rounded by biologically compatible ligands. } \\
\text { - Core: contains thousands of iron atoms that collectively increase localiron concentration enabling the } \\
\text { detection of low numbers of cell populations that contain these particles. } \\
\text { - Ligands: include silica, citrate, dextran or carboxydextran, chitosan, gelatin or starch that generally prevent } \\
\text { particle aggregation and provide hydrophilicity and stability to the internal magnetic core [27, 35]. } \\
\text { Usually, IONPs with a particle diameter }>50 \mathrm{~nm} \text { are considered as superparamagnetic IONPs (SPIONPs) } \\
\text { and those with diameter }<50 \mathrm{~nm} \text { are considered as ultrasmall SPIONPs (USSPIONPs) [36]. }\end{array}$ \\
\hline Magnetism and colloidal stability & $\begin{array}{l}\text { - Particles are colloidally stable }[27,37] \\
\text { - When exposed to a magnetic field, IONPs show superparamagnetism i.e., a strong response (magnetic } \\
\text { properties) and thereby high sensitivity in detection via MRI. } \\
\text { - Due to the magnetic properties, an external magnetic field can be used to direct IONPs to specific sites } \\
\text { within the tissue, which facilitates targeted delivery of therapeutic agents [38]. } \\
\text { - When the magnetic field is removed, IONPs lose their magnetisation vector, become highly dispersed, } \\
\text { show no magnetism at room temperature. There is almost no particle self-aggregation and phagocytic } \\
\text { uptake is prevented. }\end{array}$ \\
\hline At physiological level & $\begin{array}{l}\text { - Most IONPs are phagocytosed by the liver Kupffer cells. This promotes their utility for liver imaging [34]. } \\
\text { - Generally, nanoparticles with less than } 10 \mathrm{~nm} \text { are eliminated via the renal system whereas those with size } \\
\text { greater than } 200 \mathrm{~nm} \text { are phagocytosed. Both events are not beneficial for biomedical applications [37]. }\end{array}$ \\
\hline Biodegradability & $\begin{array}{l}\text { IONPs remain in the circulation for a long time but are biodegradable in nature i.e., get cleared from the } \\
\text { circulation by opsonins. Essentially, opsonins activate the complement system and tag the IONPs to be } \\
\text { engulfed/degraded by the phagocytic cells [39]. However, inorganic non-biodegradable IONPs may remain } \\
\text { in the environment for long periods, leading to prolonged exposure to human with unidentified conse- } \\
\text { quences. }\end{array}$ \\
\hline Half-life & $\begin{array}{l}\text { - USSPIONPs have a longer half-life in blood than SPIONPs, so these cater to a wider spectrum of imaging } \\
\text { application such as tumour perfusion imaging, atherosclerotic plaque imaging, MR angiography, and the } \\
\text { imaging of liver, lymph node and bone marrow. } \\
\text { - Also, USSIONPs are not linked with a risk of developing nephrogenic sclerosis, which is particularly use- } \\
\text { ful for patients with renal insufficiency and the approach is considered much safer than using gadolinium } \\
\text { chelates for MRI [34]. }\end{array}$ \\
\hline
\end{tabular}

Table 2 Notable features of IONP-labelling of MSCs

\begin{tabular}{|c|c|}
\hline Parameter & Features of IONP-labelling of MSCs \\
\hline MSC viability & $\begin{array}{l}\text { IONPs seem to be non-toxic and do not elicit other side-effects [40]. IONPs generally do not affect MSC viability, prolif- } \\
\text { eration and differentiation potential [27]. However, the long-term effects of these on MSC functions are yet to be fully } \\
\text { understood. }\end{array}$ \\
\hline MSC differentiation & $\begin{array}{l}\text { For successful therapy, the transplanted IONP-labelled MSCs must retain viability and differentiation capability in-vivo. } \\
\text { IONP-labelling to human bone marrow-derived MSCs (BM-MSCs) showed retention of surface markers, MSC trilineage } \\
\text { differentiation capacity, and ability to differentiate into cardiac and neuronal cell lineages in-vitro [41]. }\end{array}$ \\
\hline MSC migration & $\begin{array}{l}\text { MSCs show migration to injury sites, but the efficiency is low [42]. In rats with inflamed ear, injection of IONP-labelled } \\
\text { MSCs showed improved migration of labelled MSCs to the site of inflammation. Essentially, IONPs enhanced MSC } \\
\text { migration to injury sites and facilitated healing, thereby showing the potential for improved clinical efficacy. This was } \\
\text { also observed in-vitro wherein IONPs elevated MSC migration and homing ability (Fig. 2) [2]. }\end{array}$ \\
\hline $\begin{array}{l}\text { Adipose-derived } \\
\text { MSCs in context }\end{array}$ & $\begin{array}{l}\text { Bone marrow is the most common source of MSCs for clinical use. Using adipose-derived MSCs is considered as a poten- } \\
\text { tial alternative. In-vitro, IONP-loaded adipose-derived stem cells retained their ability of multilineage differentiation and } \\
\text { did not differ from unlabelled cells in expression levels of caspase-3, interleukins (IL)-6 and } 8 \text { and vascular endothelial } \\
\text { growth factor (VEGF) for } 4 \text { weeks following IONP-labelling [38]. } \\
\text { However, in-vitro, these cells showed variable differentiation depending on the type, duration and intensity of the magnetic } \\
\text { field applied to these cells; shorter and longer exposure times with low intensity magnetic field promoted adipogenesis } \\
\text { and osteogenesis, respectively [46]. } \\
\text { Although adipose-derived stem cells have shown promising results including neurocognitive improvement in animal } \\
\text { models [47], these cells can confer malignant features to cervical cancer cells [48]. Therefore, its clinical usage (with or } \\
\text { without IONP-labelling) for tumour treatment needs further investigation. }\end{array}$ \\
\hline
\end{tabular}




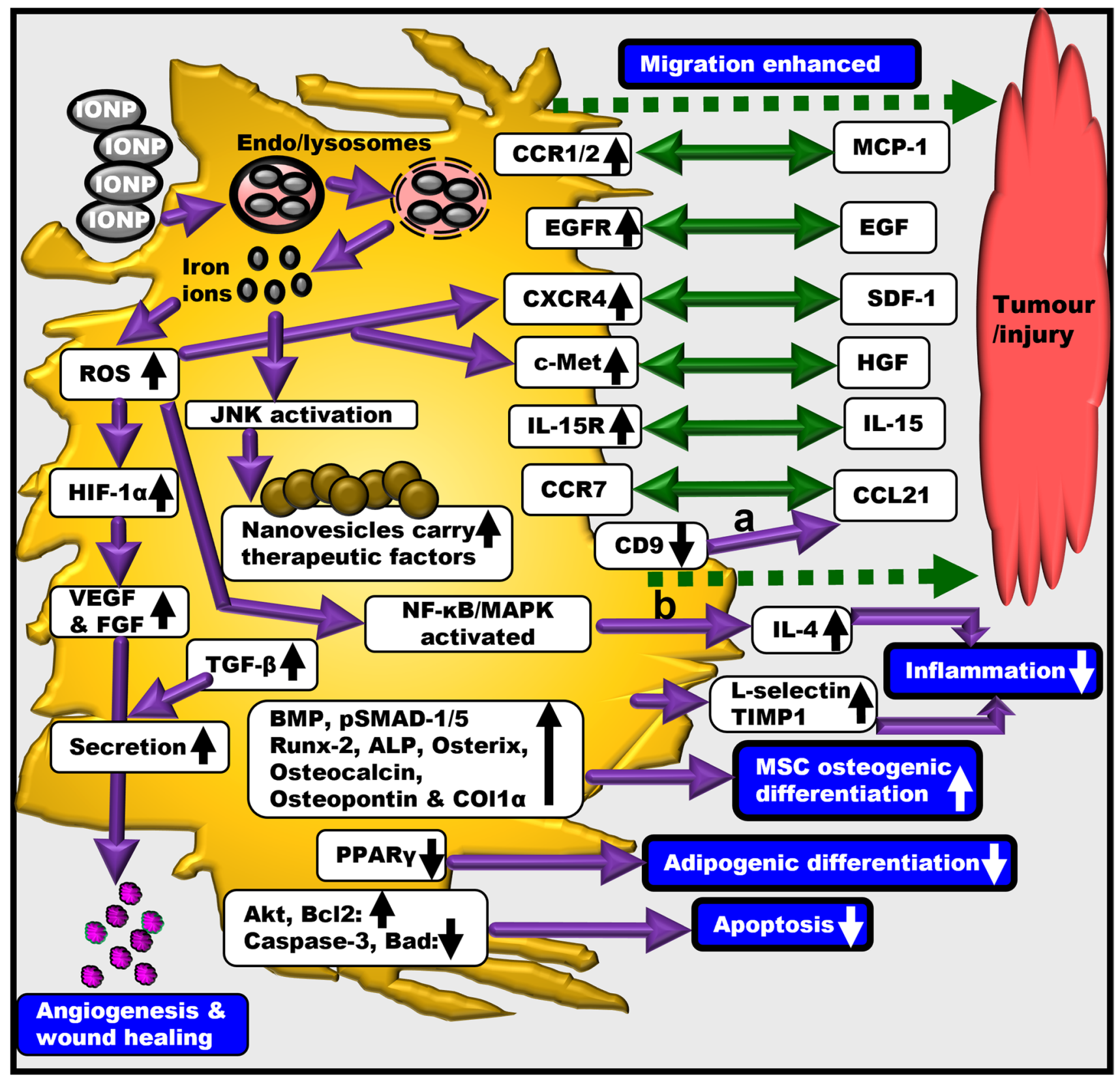

Fig. 2 Iron oxide nanoparticle (IONP)-induced alterations in MSC biology. IONPs can cause several intracellular alterations within the MSCs leading to varied responses. Increased and decreased signalling/expression/effect is shown by upward and downward pointing arrows, respectively. Chemokine-receptor pairing has been shown via double-sided green arrows. Dotted green arrows indicate MSC tropism towards tumor/injury. Interestingly, both MSCs and tumour cells can secrete TGF- $\beta$ and VEGF (a): IONP-induced reduction in CD9 expression may lead to unaltered CCL21 secretion by MSCs, thereby retaining the migration of tumour cell. The relevant study is discussed in the review [43]. (b): IONP-labelled MSCs produce increased levels of IL-4. IONPs can activate MAPK signalling in MSCs [44].
Activation of this pathway regulates the production of IL-4 and other cytokines. Genetically modified MSCs that secreted IL-4 (antiinflammatory) in response to $\mathrm{NF \kappa B}$ activation demonstrated great immunomodulatory ability and mitigated the pro-inflammatory response of macrophages [45]. ALP: Alkaline phosphatase; CCL21: C-C motif ligand-21; CXCR: C-X-C motif chemokine receptor; EGF: Epidermal growth factor; EGFR: Epidermal growth factor receptor; FGF: Fibroblast growth factor; HIF1- $\alpha$ : Hypoxia inducible factor 1 alpha; IL: Interleukin; MCP-1: Monocyte chemoattractant protein-1; PPAR $\gamma$ : Peroxisome proliferator-activated receptor gamma; SDF-1: Stromal cell-derived factor-1; TIMP-1: Tissue inhibitor of metalloproteinase 1; VEGF: vascular endothelial growth factor 
as shown in Fig. 2, IONPs can increase MSC expressions of CXCR4 and the migration-related proteins CCR 1 and c-Met [2]. Essentially, intracellularly delivered iron ions (due to IONP treatment) induce low levels of ROS [54, 55], which can elevate CXCR4 in MSCs [55-57], amongst other MSC alterations (Fig. 2). Similarly, IONPs induce elevation in MSC EGFR and this supports MSC tumour tropism (towards tumour EGF) (Fig. 2) [58]. Ironion-induced ROS also upregulates hypoxia inducible factor- $1 \alpha$ (HIF-1 $\alpha$ ) expression in MSCs, which in turn, can elevate MSC secretion of paracrine factors like VEGF (supports angiogenesis during wound repair) and basic fibroblast growth factor (bFGF) (supports angiogenesis) [59]. Essentially, HIF-1 $\alpha$ acts as a transcription factor, binds to VEGF promoter and induces VEGF expression [56, 60, 61].

Although MSCs exhibit tropism towards malignant tumours and are therefore considered as vehicles for the delivery of therapeutic materials, the exact function of MSCs following homing into tumours remains to be fully elucidated. Studies have reported both protumour and anti-tumour potential of MSCs [62]. The anti-tumour MSC mechanisms possibly involve inhibition of angiogenesis and $\mathrm{Wnt}$, Akt and NFKB signalling, and increased cell cycle arrest and apoptosis [63], while MSC pro-tumour effects [5] involve promotion of tumour growth and metastasis, as observed in hepatocellular carcinoma in-vivo [64]. Notably, iron-loading has shown to elevate mesenchymal and metastatic markers in HepG2 cells [65]. Therefore, iron-labelling of MSCs can further increase the pro-tumour potential of the MSCs. Thus, this approach must be executed with extreme caution.

Essentially, IONP endocytosis by the MSCs causes several other intracellular alterations including activation of signalling pathways and increased or decreased production of specific proteins (Fig. 2). These lead to altered MSC responses that are manifested as enhanced MSC migration towards tumour or injury, reduced inflammation and apoptosis, promotion of MSC osteogenic differentiation and reduction in MSC adipogenic differentiation (Fig. 2). IONP-labelled MSCs can produce increased levels of IL-4 (Fig. 2) in addition to elevation in other anti-inflammatory chemokines, thereby facilitating reduction in inflammation. While both IONP-labelled and unlabelled MSCs can show increased expression of TGF- $\beta$ expression that affects the wound healing process, serum levels of VEGF and anti-inflammatory cytokines IL-10 and IL-4 have been higher in rats treated with IONPlabelled MSCs than rats treated with unlabelled MSCs [57], thereby demonstrating the healing effect exerted by labelled MSCs (Fig. 2).

\section{IONPs in Combination with Carbohydrates for Labelling MSCs}

\section{Venofer}

Venofer is an $\mathrm{Fe}^{3+}$-hydroxide sucrose complex with $\mathrm{Fe}^{3+}$-hydroxide in the core surrounded by covalentlybounded sucrose molecules [66]. It is used as an infusiontreatment for patients with iron deficiency anaemia [67].

A healthy cartilage is made of chondrocytes and there are several inflammatory conditions that damage the cartilage tissue. Aiming to devise a therapeutic strategy, Venofer-labelled MSCs from patients undergoing spinal surgery were examined for viability and chondrocyte differentiation ability in-vitro. Positive results demonstrated the potential of this approach in cell tracing and checking the cellular distribution of transplanted MSCs in-vivo [68]. Following this, Venofer-labelled human BM-derived MSCs demonstrated MSC trilineage differentiation invitro (osteogenic, adipogenic and chondrogenic). When transplanted into lapine intervertebral discs in rabbits, these were successfully tracked after 3 months post transplantation [69]. Results showed the potential application of this approach in human MSC transplantation to tackle degenerate cartilaginous tissues. Accordingly, human MSCs were labelled with Venofer and transplanted into degenerated intervertebral discs in patients. Transplanted cells and their progeny were detectable for up to 8 months post transplantation, showed distribution in different parts of intervertebral discs and MSC differentiation into chondrocyte-like cells [70]. This proved the success of this approach in humans.

Since MSCs have the ability to migrate to wound/ inflammation sites and tumours [1], the therapeutic potential of Venofer-labelled MSCs against tumours was assessed. In-vitro, Venofer-labelling to dental-pulpderived MSCs (by using protamine sulphate and heparin) retained MSC viability, allowed osteogenic and chondrogenic differentiation but hindered adipogenic differentiation (Fig. 2) [67]. This can be expected because stimulation of osteogenesis can inhibit adipogenesis, but on the other hand this defies observations where excess iron has shown to favour adipogenesis over osteogenesis [3]. This indicates that both free iron (which generates ROS and affects cell signalling pathways) as well as iron bound to moieties like sucrose (as in this case) can determine MSC differentiation. Regardless, in-vitro, these cells released exosomes in the conditioned medium, which, in combination with 5-fluorocytosine, caused tumour cell death in a dose dependent manner and demonstrated great therapeutic capability. When applied intranasally in rats, labelled cells successfully migrated to intracerebral glioblastoma, 
thus proving the capability of this method in tumour tracking [67], thereby promising targeted therapy for tumours.

Magnetic hyperthermia involves heating of tissues (tumour) to a local temperature of about 40 to $50{ }^{\circ} \mathrm{C}$ using magnetic materials, which causes cellular changes resulting in apoptosis or necrosis [71]; a useful approach for cancer treatment. In a further study, Venofer-labelled MSCs were used to facilitate magnetic hyperthermia. Human MSCs expressing yeast cytosine deaminase:uracil phosphoribosyl transferase suicide fusion gene were labelled with Venofer. Labelled human MSCs released exosomes. In presence of prodrug 5-fluorocytosine, these exosomes caused tumour cell death. The MSC-released exosomes contained iron oxide that were efficiently endocytosed by the tumour cells and the treated tumour cells could be successfully ablated by magnetic hyperthermia [72]. Venofer labelling was also successfully tested in-vitro in adipose-derived MSCs for tracking via MRI [66].

\section{Ferumoxytol}

Ferumoxytol/Feraheme ${ }^{\mathrm{TM}}$ was originally designed as a contrast agent for MR [34]. It is the only FDA approved agent for intravenous treatment of anaemia in human and the only approved IONP that is used currently. Structurally, it is a carbohydrate-coated IONP i.e., magnetic core surrounded by polyglucose sorbitol carboxymethylether (carboxymethyldextran). Its particle size is approximately $17-30 \mathrm{~nm}$ and has a molecular weight of $750 \mathrm{kDa}$ [73].

Since MSCs exhibit poor ferumoxytol-uptake ability, earlier studies used protamine sulphate (clinically applicable, FDA-approved) [73] as a transfection agent to enhance ferumoxytol uptake. To overcome the issues of transfectionagent-induced undesirable effects and ferumoxytol's incapability to effectively label MSCs in cell culture with or without protamine [74], subsequent studies established protocols that allowed ferumoxytol-labelling of MSCs without the need for transfection agents and/or electroporation. For example, MSCs were labelled with ferumoxytol in-vivo by intravenously injecting it in rats [75]. This interesting procedure is depicted and elaborated in Fig. 3.

Despite the advantages, the in-vivo method (Fig. 3) cannot be applied to autologous MSC transplantations because of the consequent inability to distinguish between the ubiquitously present labelled macrophages and transplanted MSCs. Also, since cell divisions can dilute ferumoxytol labelling to below MRI detection levels, the method would not be greatly suitable where MSC expansion is required to obtain sufficient MSCs for clinical application. As such, ex-vivo MSC expansion diminishes the MSC phagocytic ability [74]. Thus, another transfection-free approach was devised that utilised a "bio-mimicry" method for labelling MSCs with ferumoxytol. This approach mimicked the in-vivo environment of the MSCs. In this approach, MSCs retained their native features including cell size, recovered their phagocytic ability and showed ferumoxytol uptake that was comparable to that obtained by using transfection agents $[74,76]$. This method has been successfully used in labelling MSCs with dextran-coated IONPs [77].

Ferumoxytol promises a wide range of clinical applicability. Osteoarthritis is a chronic joint inflammation characterised by cartilage degradation. Ferumoxytol-labelled MSCs helped determine that MSCs may modulate synovial inflammation. In a mouse model of osteoarthritis, intra-articular injection of ferumoxytol-labelled MSCs followed by MRI tracking showed sustenance of the signal in knee joints for up to 4 weeks. Also, there were decrements in MRI scores related to fluid oedema, pro-inflammatory cells and synovial fibrosis, and an increment in macrophage infiltration with preponderance of homeostatic macrophages, collectively demonstrating the anti-inflammatory characteristics of these labelled MSCs [78]. When ferumoxytol-labelled MSCs were transplanted in mice to alleviate calvarial defects, cells could be monitored and quantified over time via magnetic particle imaging, thereby promising useful MSC-based approaches for bone regeneration [79].

Alzheimer's disease, a type of dementia, is characterised by constant decline of brain functions including thinking skills. Ferumoxytol-labelled human umbilical-cord-derived MSCs did not show cell toxicity, retained stemness in-vitro, and these cells were successfully engrafted into the brain of mice models of Alzheimer's disease. Administrated MSCs could be detected in-vivo for up to 14 days at the site of injection via MRI. The success of this approach promised tracing of transplanted MSCs in real time in patients with Alzheimer's disease [80].

In head and neck squamous cell carcinomas, smaller lymph nodes can harbour clinically occult metastases, which can make routine imaging modalities challenging. Previously, ferumoxytol was studied as an intra-tumoral contrast agent in MRI for intracranial malignancies and in prostate cancer. A subsequent study aimed to assess the feasibility of Ferumoxytol dynamic contrast enhanced-weighted MRI relative to gadolinium-based dynamic contrast enhancedMRI for nodal and tumour imaging in five patients with head and neck squamous cell carcinomas. However, this study was prematurely terminated because of FDA black box warning [81].

\section{Dextran}

Parkinson's disease is a neurodegenerative disease characterised by the death of dopaminergic neurons. Brain iron accumulation is believed to play a role in the pathogenesis $[82,83]$. Chung et al. exploited the migration and differentiation ability of MSCs and demonstrated for the first time 
Fig. 3 In-vivo and ex-vivo approaches of labelling MSCs with ferumoxytol. This figure is based on the elegant work done by Khurana et al. (2013). Prior to administration, MSCs could be labelled with IONPs ex-vivo or in-vivo, as depicted in the figure. Essentially, in the in-vivo labelling approach, ferumoxytol was taken up by rat reticuloendothelial system and labelled BM-MSCs were obtained from the rat. The label was retained in the cells throughout the steps of harvesting and ex-vivo expansion. Compared to unlabelled control cells, in-vivo-labelled MSCs showed higher iron content and shorter $\mathrm{T} 2$ relaxation times upon transplantation into rats with osteochondral knee defects. In-vivo labelling approach is more effective, and it reduces the risks of contamination and biological alterations that can occur during the ex-vivo labelling procedures. However, in-vivo methods of labelling present limitations, as discussed in the review

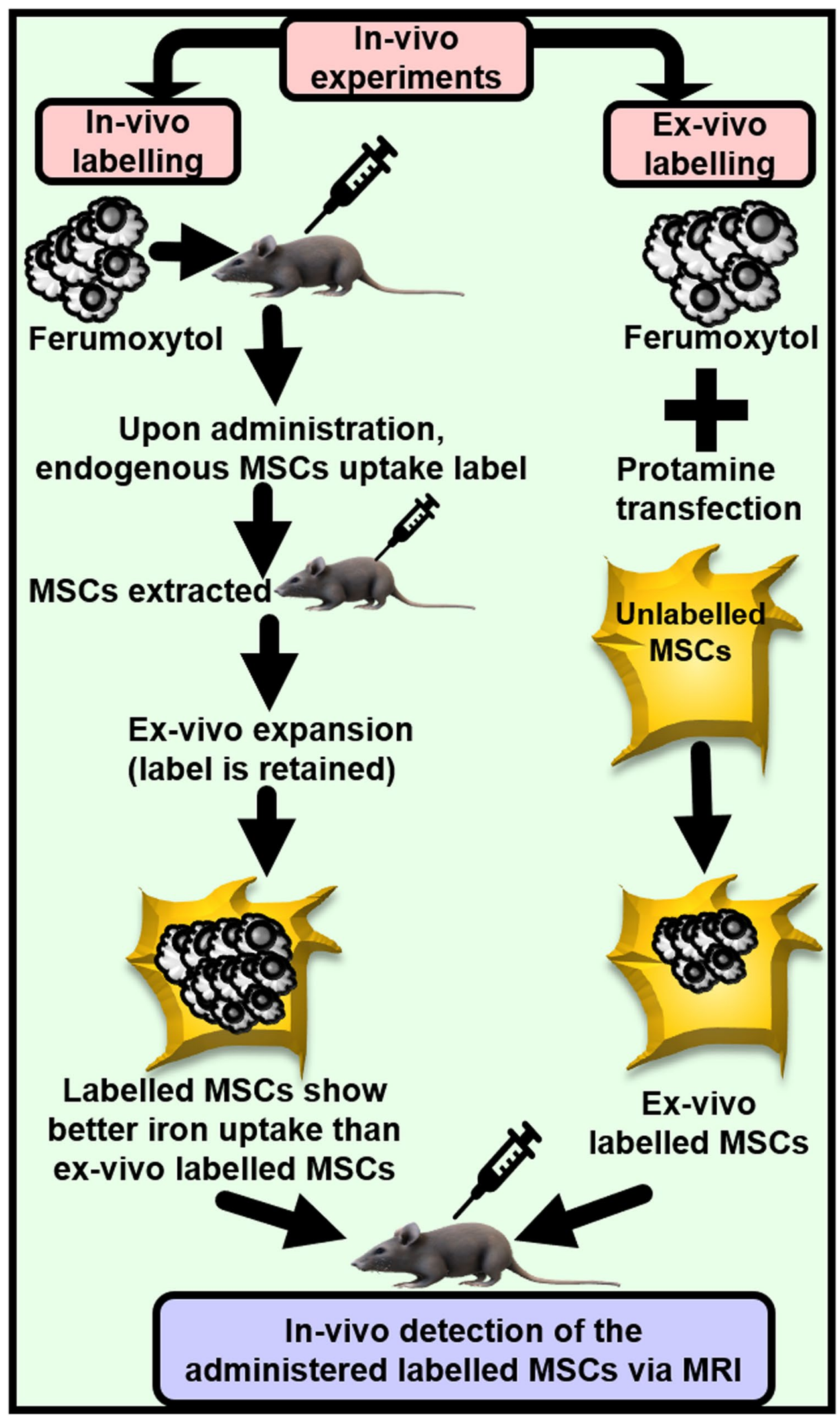


that dextran-coated IONPs can enhance the therapeutic benefits of MSCs in a mouse model of Parkinson's disease. IONP-dextran-labelled human BM-derived MSCs migrated towards the sites of damaged dopaminergic neurons in the mice brain. Also, these dextran-coated IONPs improved the ability of MSCs to rescue host dopaminergic neurons, increased MSC migration ability (due to elevated CXCR4, EGFR and IL-15R) (Fig. 2) and enhanced MSC differentiation into dopaminergic-neuron-like cells to replace the damaged neurons and secrete neurotrophic factors [5]. Similarly, MSCs appeared as a promising modality for Alzheimer's disease when human Wharton's jelly-derived MSCs were labelled with dextran-coated IONPs and magnetically delivered to the hippocampus of a rat model of Alzheimer's disease. These rats showed memory and cognitive improvement [77].

Untreated chronic liver pathologies can progress through the stages of fibrosis, cirrhosis and cause predisposition to hepatocellular carcinoma [84]. Dextran-coatedIONP-labelled BM-MSCs for treatment showed promising results when these cells successfully engrafted in rats with fibrotic livers, and promoted fibrosis-regression and inhibited dysplasia [85]. This could be partly attributed to MSC's anti-inflammatory effect as it can reduce the levels of macrophage-produced inflammatory cytokines like tumour necrosis factor (TNF)- $\alpha$ and IL- $1 \beta$ as well as TGF- $\beta$, and IL-6 (the latter two cytokines can be pro or anti-inflammatory). Also, MSCs demonstrate antifibrotic effects by secreting matrix metalloproteinases [86].

Interestingly, the efficacy of MSC therapy depends on the microenvironment of the injured liver. MSC transplantation into liver-damaged mice reduced liver fibrosis and the MSCs differentiated into hepatocyte-like cells and smooth muscle cells. However, in mice with liver fibrosis/cirrhosis but with macrophage depletion in the liver, fibrosis reduced significantly more than the former group without macrophage depletion. This difference was attributed to the pro-inflammatory and fibrogenic nature of macrophages in liver pathologies. Thus, data indicated that the hepatic niche can determine the outcome of the transplanted cells and therefore it should be altered for better clinical outcomes [86]. Along similar lines, administration of IONP-labelled BM-MSCs in rat models of cirrhosis and hepatocellular carcinoma helped restore normal histologic architecture, reduced cirrhosis, and reduced tumour mass, respectively. Here, IONP-labelled MSCs facilitated both detection and therapeutics simultaneously [87].

MSCs are known to exhibit both pro-tumour and antitumour effects [62]. IONP-dextran combination strengthened the anti-tumour effect of anti-tumour MSCs and reversed the pro-tumour effects of pro-tumour MSCs; thereby showing a potential application in MSC-based cancer therapy. In-vitro, dextran-coated-IONP-labelled human MSCs promoted more migration of the MSCs towards cancer cells compared to unlabelled human MSCs, partly due to IONP-dextran-induced elevation in CXCR4 (Fig. 2). Simultaneously, these IONPs inhibited colony formation of cancer cells (cell lines) and reduced the cancer-mediated angiogenesis and differentiation into fibroblasts of pro-tumour MSCs. Results were replicated in-vivo. When human MSCs labelled with dextran-coated IONPs were transplanted in a mice model of melanoma, an anti-tumour mechanism was activated in the MSCs, whereby pro-tumour mechanisms were inactivated that transformed pro-tumour MSCs into anti-tumour MSCs [51].

The chemokine C-C motif ligand-21 (CCL21) and the protein $\mathrm{CD} 9$ are amongst the many proteins and chemokines that play a role in cancer cell migration. Expression and secretion of CCL21 by human MSCs can facilitate chemotactic attraction to cancer cell lines. CD9 is a transmembrane protein that is expressed on several cell types including cancer cells and MSCs, and on the exosomes released from cells. It has a role in intercellular communications that mediate cancer cell migration and metastasis [43].

In a study, media of MSCs that were incubated with either ionomycin or dextran-coated IONPs were used to study migration of melanoma cell line. The study concluded that cellular CD9 had an inhibitory effect on CCL21 expression. Essentially, in human MSCs, ionomycin increased cellular CD9 expression, which reduced CCL 21 secretion by MSCs, which lessened chemoattraction and thereby decreased the migration of melanoma cell line. In contrast, dextran-coated IONPs reduced MSC's cellular expression of CD9, showed unaltered CCL21 secretion by MSCs (compared to control) and therefore unaltered chemoattraction and migration of melanoma cell line (Fig. 2) [43]. Thus, MSC treatment with dextran-coated IONPs and ionomycin helped envisage a pharmaceutical strategy involving CD9 to prevent cancer metastasis.

MRI tracking of injected IONP-labelled MSCs has shown promising results in animals but was not evaluated in humans until recently. Mathiasen et al. conducted the first contextual clinical study in human that evaluated the usage of dextran-coated TAT-conjugated IONP-labelled autologous BM-MSCs in intramyocardial transplantation of these cells in patients with chronic ischemic heart disease. Labelled MSCs could be tracked via MRI for up to 14 days after transplantation without compromising on safety [88].

Ferucarbotran (Resovist $\left.{ }^{\circledR}\right)$ is an IONP coated with carboxydextran. Although it is still available in some countries like Japan, it has been discontinued from clinical usage since 2009 by several European countries [89]. Therefore, this IONP isn't discussed here. Feridex, another dextran-coated IONP has been discontinued [89]. 


\section{Glucosamine}

Glucosamine is a natural monosaccharide which makes the glycosaminoglycans found on several surfaces of joints (cartilage tissue). It is believed to provide chondroprotection and target prospective chondroprogenitors like the MSCs [90]. Its utility was further explored during IONP-labelling of MSCs. MSCs were labelled with IONPs, USIONPs and glucosamine-tagged USIONPs. Upon transfection with poly-lysine, the latter showed biocompatibility, better iron uptake by the MSCs and therefore higher MRI sensitivity invitro than the other combinations. Results replicated in-vivo where MRI was used for cerebral tracking of glucosaminetagged USIONPs in rats. Data indicated that the presence of glucosamine (with poly-lysine) greatly enhanced cellular uptake of USIONPs and enabled better detection [91].

\section{IONPs in Combination with Non-carbohydrate Polymers for MSC Labelling}

\section{Poly(L-Lysine): The Transfection Agent}

There are a multitude of examples were poly-lysine has been used successfully used as a transfection agent, promoting IONP uptake by MSCs. Some examples are discussed here.

Photoacoustic imaging is a technique wherein following absorption of a short laser (light) pulse, the tissue expands due to heat and generates a photoacoustic wave. Essentially, the light pulse excites the contrast agent creating ultrasonic waves. The signal is detected by ultrasonic transducers and processed into a 3-D high-resolution image [27, 92]. This non-invasive imaging technique is accessible without ionizing radiation, offers deep penetration and higher resolution than MRI and enhances the contrast of traditional ultrasound at an affordable price. Prussian blue nanoparticles are currently being investigated as photoacoustic contrast agents [93]. Unlike the frequently used gold nanoparticles, Kim et al. labelled human MSCs with Prussian blue-poly(Llysine) nanocomplexes for photoacoustic imaging. They prepared Prussian blue nanoparticles using a combination of ferric chloride and potassium ferrocyanide, complexed with poly-L-lysine, and labelled human MSCs with this complex. Cellular uptake of these particles was achieved, iron content was several folds higher than citrate-conjugated Prussian blue nanoparticles, and the cells could differentiate into adipocytes and osteocytes without alterations in viability, proliferation, and cytokine secretion. Labelled MSCs showed strong photoacoustic contrast in-vitro and in-vivo (in mice for 14 days), thereby offering good spatial and temporal resolution [93].
Later, Mishra et al. longitudinally tracked (for 21 days post-transplantation) IONP-poly-L-lysine labelled MSCs in mice with traumatic brain injury using MRI. Data revealed that damaged tissue was replaced with healthy tissue and MSCs incubated with the aforementioned complex in a ratio of $50: 1.5 \mu \mathrm{g} / \mathrm{ml}$ for $6 \mathrm{~h}$ were optimised to increase the labelling efficiency [94]. Low molecular weight protamine is a non-toxic substitute of protamine with effective cell penetrating property [95]. When IONPs were conjugated with this non-toxic protein transduction domain, the iron content in the labelled MSCs was much higher than cells labelled with only IONP and IONP-poly-L-lysine. Also, the MSC differentiation capacity remained unaltered [96].

\section{Poly(Lactide-Co-Glycolide) and Poly(L-Lactide)}

With time, there is a decrease in the MRI signal from the internalised IONPs because of cell proliferation and exocytosis of IONPs. Proliferation of IONP-labelled transplanted cells allows distribution of particles between the daughter cells leaving only a small percent of cells containing the particles after a few cycles. Xu et al. attempted to tackle this by exploiting two properties of nanoparticles: a) polystyrenebased microparticles exhibit a strong signal, and b) bigger particles show slower exocytosis rate. They hypothesised that 1-2 $\mu \mathrm{m}$-sized particles with strong MRI signal would decrease particle exocytosis and enable better and longer longitudinal tracking of MSCs. Accordingly, biodegradable poly(lactide-co-glycolide) microparticles loaded with IONPs were used to label MSCs. In-vitro and in-vivo experiments (in mice) revealed enhanced cellular localisation of iron, which increased the signal to noise ratio and offered better detection via MRI. Larger particle size increased resident time within the cells and provided longer detectable time of labelled MSCs in comparison to IONPs alone. This occurred without compromising MSC viability, proliferation, migration and homing at the sites of inflammation [97].

In another study, IONPs were encapsulated in poly(lactide-co-glycolide) microspheres and those with $1.38 \%$ IONPs showed highest adherence of BM-MSCs invitro after $48 \mathrm{~h}$ of co-culture. These microspheres significantly promoted osteoblast differentiation of BM-MSCs, as evidenced by detecting alkaline phosphatase (ALP), collagen-1, osteopontin and osteocalcin; the osteogenesis-related proteins (Fig. 2). Administration of these microspheres into rat femoral bone together with an external magnetic field remarkably improved the bone defect [98].

Preservation of MSC functionality is a prerequisite for the success of MSC therapy. Human MSCs were successfully labelled with iron oxide-poly(L-lactide) nanoparticles and the fluorescent dye $\mathrm{N}$-(2,6-diisopropylphenyl)-perylene3,4-dicarbonacid-imide without any impact on viability, differentiation, proliferation, clonogenicity, adhesion, and other 
immunomodulatory and phenotypic properties. Following subcutaneous implantation in rats, these could be detected via MRI for several weeks [99].

\section{Polydopamine}

Dopamine is a natural neurotransmitter that can spontaneously form polydopamine via autopolymerisation in-situ [100]. Polydopamine is biodegradable, biocompatible and therefore, widely used to coat IONPs for biological applications [2]. Polydopamine-capped IONPs were successfully incorporated in MSCs without alteration in MSC stemness. This labelling enhanced their migration ability via CXCR4 upregulation, as demonstrated via accumulation of labelled MSCs at burn injury sites in a rat model. Labelled cells also exhibited healing properties (increased anti-inflammatory factor IL-4), as indicated by reduction in inflammation at the injury sites (Fig. 2), thereby showing the utility of this approach in healing burn wounds [57].

In rat BM-MSCs labelled with polydopamine-capped IONPs, the latter improved the biocompatibility and stability of the IONP core. In-vitro, polydopamine-capped IONPs retained MSC differentiation characteristics. However, there were no major differences in results between MSCs labelled with polydopamine-capped IONPs and.

MSCs labelled with polydopamine-devoid IONPs in the following parameters: IONP-induced reduction in inflammation (in-vivo), MSC release of VEGF (which promotes angiogenesis and neovascularisation of damaged tissue) (invitro) and migration (in-vitro). Interestingly, MSC expressions of migration-related proteins c-Met and CCR1 induced by IONPs alone (Fig. 2) far exceeded the levels induced by polydopamine-capped IONPs [2]. Thus, polydopaminecapping of IONP can offer advantages but its usage should consider the outcome desired.

Similarly, human umbilical cord MSCs were labelled with polydopamine-coated IONPs. In-vitro, labelled MSCs showed hemocompatibility, biocompatibility, low cytotoxicity and enhanced migration ability. Labelled cells were then administered in the femoral head in rat models of osteonecrosis, a chronic irreversible disease in human that eventually leads to joint dysfunction. In presence of an external magnetic field, these cells enhanced osteogenic effects, as evidenced by elevations in Runx-2 and Osterix (osteogenic proteins) and Akt and Bcl-2 (anti-apoptotic proteins), and decrements in caspase- 3 and Bad (apoptotic proteins) (Fig. 2). Compared to controls, in cases of polydopaminelabelled MSCs, rat serum levels of IL-4 and IL-10 (antiinflammatory cytokines) were higher and TNF- $\alpha$ and IL-6 (pro-inflammatory cytokines) were lower. The effects were even more pronounced in presence of the external magnetic field. These collectively mediated bone repair and suggested a novel strategy for treating osteonecrosis [100].

\section{IONPs in Combination with Elements for Labelling MSCs}

\section{Ruthenium/Selenium}

Human umbilical cord MSCs were labelled with IONPs bound to ruthenium $\left(\gamma-\mathrm{Fe}_{2} \mathrm{O}_{3} @ \mathrm{Ru}\right)$ and selenium $\left(\gamma-\mathrm{Fe}_{2} \mathrm{O}_{3} @ \mathrm{se}\right)$. Treatments elevated gene expressions of bone morphogenetic protein (BMP), ALP, RUNX-2, osteocalcin, osteopontin, collagen- $1 \alpha$ and p-SMAD-1/5 in MSCs (Fig. 2) [101]. This reminds us of the iron-induced upregulation of the TGF- $\beta$ pathway components TGF- $\beta$ receptor-2 and p-Smad-2 observed in murine hepatic stellate cells [102]. Thus, the aforementioned elevation in p-SMAD-1/5 in MSCs could be due to the iron component in $\gamma-\mathrm{Fe}_{2} \mathrm{O}_{3} @ \mathrm{Ru}$ and $\gamma-\mathrm{Fe}_{2} \mathrm{O}_{3} @$ se. MSC differentiation into osteoblasts was induced without cell cycle arrest or oxidative stress. However, $\mathrm{Fe}_{2} \mathrm{O}_{3} @ \mathrm{Ru}$ diffused more effectively in the cytoplasm, localised in the nuclei of MSCs, strongly induced osteogenesis and inhibited adipogenic differentiation [101]. Indeed, where MSCs were cultured with $\mathrm{Fe}_{2} \mathrm{O}_{3} @ \mathrm{Ru}, \mathrm{p}-\mathrm{SMAD}-1 / 5$ was further upregulated and peroxisome proliferator-activated receptor gamma (PPAR $\gamma$ ) (adipogenic marker) was downregulated (Fig. 2). This indicated that $\mathrm{Fe}_{2} \mathrm{O}_{3} @$ Ru-mediated preferential osteogenic differentiation of MSCs could be regulated by the BMP-SMAD-1/5 pathway [101], which usually modulates the upregulation of osteogenic genes and down-regulation of adipogenic genes [3,101].

\section{Gold}

IONPs were combined with gold so that the nanoparticle could be detected by both MRI and photoacoustic imaging; the latter offers several advantages, as discussed previously. Essentially, GFP-conjugated BM-MSCs were successfully labelled with gold-coated IONPs, which did not alter MSC migration and differentiation capacities in-vitro. Labelled MSCs were introduced in mice through the carotid artery to visualise these cells in the brain tumour of mice and assess MSC homing via MR and photoacoustic imaging. After $72 \mathrm{~h}$ of injection, the photoacoustic signal emitted from the tumours of labelled MSCs was more enhanced than tumours with unlabelled MSCs. MRI matched the results of photoacoustic imaging and showed significant progressive (over time) hypointensity of the tumour with gold-coated IONP-labelled MSCs. Histological examination revealed co-localisation of GFP fluorescence and iron, which indicated that gold-coated IONP-labelled MSCs carried the IONPs even after $72 \mathrm{~h}$ of injection. Notably, during initial in-vitro experiments, 
lipofectamine was used as a transfection agent which enhanced the uptake of gold-coated IONPs and did not affect viability but decreased proliferation. Lipofectamine was not used in subsequent in-vivo experiments because it further decreased proliferation of labelled MSCs and reduced MSC viability over time [92], thereby providing an example of the disadvantage of using transfection agents.

Despite the therapeutic effects of MSCs, these can show low viability, poor homing and a potential risk of oncogenesis induced by direct MSC administration at the wound site. Im et al. aimed to mitigate these limitations by exploiting the ability of endocytosed IONPs inside the endosomes to undergo degradation into ions due to the low $\mathrm{pH}$ of the endosomes. Thus, they designed $\mathrm{pH}$ sensitive nanoparticles that allowed endocytic release of iron ion inside the MSCs. High-passage-number (P12) MSCs were treated with goldiron nanoparticles. Intracellular iron ions elevated MSC HIF- $1 \alpha$ expression, which in turn elevated VEGF expression (essential for wound healing). This resultant iron-ioninduced upregulation of VEGF expression in these high-passage-number labelled MSCs was comparable to the amount released by low-passage-number MSCs without the goldiron nanoparticle treatment. Administration of this highpassage-number-derived labelled conditioned medium into a mouse model of skin wound led to better angiogenesis compared with the group injected with unlabelled conditioned medium from high passage MSCs. Results obtained were similar to that in mice injected with conditioned medium from low passage MSCs; the results were enhanced angiogenesis, re-epithelization and tissue remodelling [103]. This study introduced a new approach of using MSC conditioned medium instead of MSCs to mediate MSC therapeutics.

\section{Zinc}

Zinc ions are generally redox stable and induce antioxidant effects in cells [104]. Like others, Kim et al. used the principle of stimulating gene expression via intracellular ions and hypothesised that the combination of two metal ions, zinc and iron (dual ion delivery system) will induce zincion-mediated osteogenesis and iron-ion-mediated paracrine secretion by the MSCs. Thus, aiming to improve the osteogenic differentiation of human MSCs and promote angiogenesis simultaneously, zinc-based IONPs were synthesised. These were dissolved in a weak acid that mimicked low $\mathrm{pH}$ within the endosomes. In-vitro, zinc-IONP-labelled MSCs showed enhanced osteogenic expression (RUNX-2 and ALP) and increased secretion of VEGF (angiogenic paracrine factor) (Fig. 2). The concurrent intracellular release of zinc and iron ions modulated the subtle increase in ROS in the MSCs without causing cytotoxicity. This augmented MSC osteogenic potential and promised useful applications of this approach in future [104]. Notably, if MSC therapeutic efficacy is to be enhanced via delivery of intracellular ions, then it is crucial to adjust the concentrations of the ions delivered. This is because intracellular ion homeostasis is essential for cell viability and functionality. For example, high zinc ion concentration can dysregulate intracellular iron ion homeostasis, cause cellular iron overload and induce iron-ion-mediated cell death called ferroptosis [105].

To tackle the challenge of compromised stem cell labelling efficiency and low stem cell homing efficiency, MSCs were labelled with zinc-doped IONPs in combination with the amphiphilic polymer hyaluronic acid-cholanic acid. This allowed effective MRI-guided delivery of MSCs to the target sites, helped track MSCs in-vivo and improved MSC homing into mice models of glioblastoma and traumatic brain injury. This occurred without notable cytotoxicity and phenotypic alterations in MSCs, thus allowing targeted delivery of stem cells [56].

\section{IONPs in Combination with Compounds and/ or Stains for MSC Labelling}

\section{Silica}

MSC-labelling with IONPs in combination with silica (and associated elemental complexes) has gained foothold in the field. When human MSCs were labelled with silica-coated IONPs along with FITC-incorporated mesoporous silica, IONP uptake was enhanced without affecting cell viability and differentiation ability [106]. Distinct from several previous studies that used transfection agents to promote IONP uptake by MSCs, Harrison et al. showed that silicacoating of IONPs to label human MSCs allowed rapid cellular uptake of the particles without any transfection agent. MSC viability, surface markers and differentiation capacity remained unaltered. When silica-IONP-labelled MSCs were seeded on a porous collagen scaffold, followed by exposure to a magnetic field, these cells showed directed migration in-vitro. This could be very useful in seeding procedures for 2D culture and 3D tissue-engineered scaffolds and can reduce the cell dosage required for Prochymal therapy [35].

Additional surface modification of silica-coated IONPs with amine not only allowed incorporation into BM-MSCs and localisation in lysosomes in the absence of transfection agent, but also increased the labelling efficiency and MRI detection sensitivity by 2-5 fold [107]. Similarly, BMMSCs labelled with amine-modified-silica-coated IONPs retained cell viability, osteogenic and adipogenic differentiation potential, and increased migration ability in-vitro (increased SDF-1 and CXCR4 expressions) (Fig. 2). When injected in rabbits with osteonecrosis bone defect, the label helped to track MSC homing at the defect site via MRI; 
homing being accelerated via poly(lactic-co-glycolic acid)/ tricalcium phosphate scaffold to mediate tissue repair [108]. This showed the potential of this system not only in tracking MSCs but also in accelerating homing of the transplanted MSCs onto injury sites.

A concern in labelling MSCs with IONPs is oxidative damage to DNA, lipids and proteins. Novotna et al. observed oxidative damage in human BM-MSCs due to IONP-labelling, so lowering the IONP concentration was recommended [109]. Following this, labelling of rat MSCs with a nontoxic dose of silica-coated cobalt-zinc-iron nanoparticles (using poly-L-lysine) did not show oxidative damage to macromolecules. Subsequent transplantation of labelled rat MSCs into rat brain showed no increase in oxidative damage to the macromolecules in the brain, compared to control unlabelled MSCs. Therefore, this method was considered safe for tracking transplanted cells via MRI [110]. Thus, silica-coated IONPs showed a huge potential in targeted cell-based therapy and in mediating theranostics, which is a combination of therapy and diagnostics.

\section{Polyethylene Glycol}

A potential for theranostics was also observed when placenta-derived MSCs were used to ameliorate mouse glioblastoma, an aggressive type of brain and spinal cord cancer in human. Hsu et al. labelled these MSCs with polyethylene-glycol-coated IONPs. Polyethylene glycol coating to IONPs allowed better uptake of these particles by MSCs and showed no cytotoxicity or alteration to MSC proliferation or stemness. Labelled cells were injected in mice and tracked for movement towards the tumour cells (glioblastoma stem-like cells that are thought to be responsible for glioblastoma tumour instigation and sustenance) in real time via MRI. Mediated via the chemokine ligand 5 and augmented by preconditioning with hypoxia, these placentaderived MSCs showed better migratory potential towards glioblastoma stem-like cells and across the blood-brain barrier compared to BM-MSCs. The success of this approach promised tracing of the infiltration of therapeutic MSCs into the tumour, and helped envisage targeted therapy for brain tumours in the future [111]. Likewise, IONP-labelled human amniotic membrane-derived MSCs exerted protective effects against isoproterenol-induced myocardial injury in rats by improving cardiac function and reducing fibrosis. This involved reducing inflammation via the NF- $\mathrm{KB} / \mathrm{MAPK}$ pathway; injury induced elevation in NF- $\mathrm{KB}$ was reversed by labelled MSCs in presence of an external magnet [112].

\section{Combination of Silica and Polyethylene Glycol}

While a complex of iron-iron oxide ( $\mathrm{Fe} @ \mathrm{FeOx})$ nanoparticles has been recognised as a promising MRI contrast agent for long, silica-coated Fe@FeOx nanoparticles accompanied by polyethylene glycol chains improved their biocompatibility and showed better darkening effect than Resovist ${ }^{\circledR}$ (Ferucarbotran), the reference contrast agent available in Japan. This combination neither showed any major cytotoxicity on human colon cancer cell line and non-tumoral fibroblast cell lines nor haemolytic activity against human RBCs, thus proving as a promising combination to detect early small tumours [113].

\section{Fluorophore}

Considering the potential of human MSCs to promote repair after stroke, clinical-grade human MSCs were labelled with fluorophore-tagged micrometre-sized IONPs without the use of transfection agent. Data showed no alterations in MSC viability, phenotype, or differentiation capacity in-vitro. When these labelled MSCs were introduced in a rat model of stroke, MSCs could be tracked in-vivo via MRI and fluorescent microscopy for up to one month after MSC administration. This approach can be very useful to formulate optimal route and dosing of cells, particularly for in-vivo MRI studies following stroke. However, it raises the usual concern of the release of IONPs from dead MSCs [114].

\section{Rhodamine B}

Pavon et al., by using the IONP-rhodamine B combination, showed that the MSCs can contribute to tumour progression. CD133+ stem cells of glioblastoma (brain/spinal cord cancer) secrete various chemokines including MCP-1 and SDF-1 that play a role in MSC tropism. Cultured human umbilical cord blood MSCs expressed the receptors for these secreted cytokines, namely CCR2 and CXCR4, respectively, and their associations induced MSC migration towards the CD133+ stem cells of glioblastoma (Fig. 2). When IONPrhodamine-B-labelled MSCs were administered into the caudal vein of rats, these MSCs crossed the blood brain barrier and showed migration towards the tumour. However, later, this led to tumour development and invasiveness, and showed a large number of cycling cells, indicating promotion of tumour growth, an undesirable event. Therefore, the usage of MSCs as carriers of therapeutic materials to tackle cancer should be applied with great caution [50].

In the absence of transfection agent, BM-MSCs were labelled with silica-coated fluorescent magnetic nanoparticle (ferrite core) containing rhodamine B isothiocyanate. When these were intra-splenically injected, cells could be successfully tracked in a rat model of liver cirrhosis, providing both optical and magnetic features [115]. Similarly, IONP-rhodamine B (and oleic acid) combination was used to label mouse BM-MSCs. In-vitro, this induced the expression of ROS and CXCR4 in the MSCs, and together with 
the elevated expression of SDF-1 in the injured tissue, this likely activated CXCR4-SDF-1 signalling; a mechanism known to enhance chemotactic activity (Fig. 2). Following the intranasal delivery of labelled MSCs in mice with olfactory bulb injury, MSCs were guided by a permanent magnet to promote migration to the injured olfactory tissue so that homing of MSCs could be enhanced in-vivo [55].

Despite successful cell homing in-vivo, whether the usage of stains negatively affected cell properties required confirmation. Thus, different vital stains were assessed in-vitro. MSCs labelled with Molday ION Rhodamine B ${ }^{\mathrm{TM}}$ (rhodamine B labelled-IONP) retained MSC viability and differentiation potential, increased sensitivity [116] and showed some superior results compared to MSCs labelled with CellTrackerTM, Green CMFDA, and eGFP-mRNA (genetic pretag). Labelling MSCs with the latter group of stains altered the metabolic activity and morphology of the MSCs. Overall, while the gene expression of the growth factors $C N T F$, $B D N F, N T 3$ and $P S A P$ remained stable post labelling, alterations were observed in the gene expressions of the growth factors $I G F, E G F, G D N F$ and $H G F$ [117]. Thus, further experiments are necessary to rigorously assess the effects of stain-tagging to MSCs and evaluate whether this approach has essential and/or superior clinical benefits.

\section{DAPI}

An issue with MRI tracking in-vivo is the detection of signal generated by macrophages that engulfed IONPs released from dead cells. 4', 6-diamidino-2-phenylindole dihydrochloride (DAPI), a fluorescent DNA dye, is frequently used to label and trace stem cells as well as visualise nuclei under fluorescent microscope. Therefore, labelling MSCs with DAPI in addition to IONPs can resolve the aforementioned issue. Rat BM-MSCs were co-labelled with Feridex (withdrawn from market) and DAPI using poly-L-lysine as transfection agent. When labelled cells were transplanted via hepatic artery into rat livers, cells could be detected invivo via MRI for up to 7 days post transplantation [118]. In another study, rabbit MSCs were co-labelled with IONPs and DAPI and transplanted via intravenous injection into rabbits with liver tumours to assess MSC tumour-homing capacity via MRI. Histological analysis revealed that IONP distribution, as visualised via Prussian blue stain, matched with the DAPI stained fluorescent nuclei i.e. iron co-localised with DAPI. These cells localised in the tumour with high specificity and could be tracked for 7 days in-vivo via MRI [49].

\section{Prussian Blue Nanocubes}

The inability to track the transplanted cells in real time hinders the full potential of cell therapy and regenerative medicine, particularly in spinal cord injuries. To tackle this, specifically formulated Prussian blue nanocubes (PBNCs) that contain IONPs were prepared to achieve multimodal MR and photoacoustic contrast. Human adipose-derived MSCs were labelled with PBNCs and labelled MSCs were injected into rat spinal cord ex-vivo while ultrasound and photoacoustic images were acquired. These imaging approaches guided the needle during MSC injection, and MRI imaging was enhanced as PBNCs acted as contract agents. Thus, a combination of ultrasound, photoacoustic imaging and MRI was used to allow multimodal detection. This approach detected low concentration of MSCs and tracked cells in the spinal cord post-administration, thereby promising applications in intra-operative and post-operative situations [119]. Similar PBNCs have been designed by other groups that can act as photoacoustic and MR contrast agents and are useful for diagnostic and therapeutic applications [120].

\section{IONPs in Combination with DNA Improve MSC Transfection}

Due to the limitations of viral vectors as gene delivery systems, a non-viral transfection approach like usage of DNA vectors is sought for biomedical applications. Distinct from the commonly used coated IONPs, Margo et al. used naked surface active maghemite nanoparticles. These uncoated IONPs were bound directly and covalently to DNA, and these acted as vectors for MSC transfection. Essentially, a plasmid containing a GFP tag (gene) was directly absorbed onto surface active maghemite nanoparticles, which formed a DNA nano-vector. This was spontaneously internalised by horse-blood-derived MSCs, and the cells showed higher levels of GFP than that expressed in cells transfected by lipofectamine, even without an external magnetic field (Fig. 4a). Excellent transfection efficiency was observed, which was attributed to the physical/chemical and hydrodynamic properties of the IONP-DNA complex. In essence, the method demonstrated a reliable tool for gene delivery and emergence of a novel DNA nano-vector that can help achieve effective MSC transfection [121].

\section{IONPs in Combination with Albumin and Fibroblast Growth Factor-2 (FGF-2)}

The most abundant serum protein albumin is widely used in research because of its biodegradable nature, high stability in blood, and biocompatibility [122]. Coating IONPs with albumin can prevent particle agglomeration, and albumin is almost inert for differentiation of cells. Albumin-protected IONPs were internalised by 


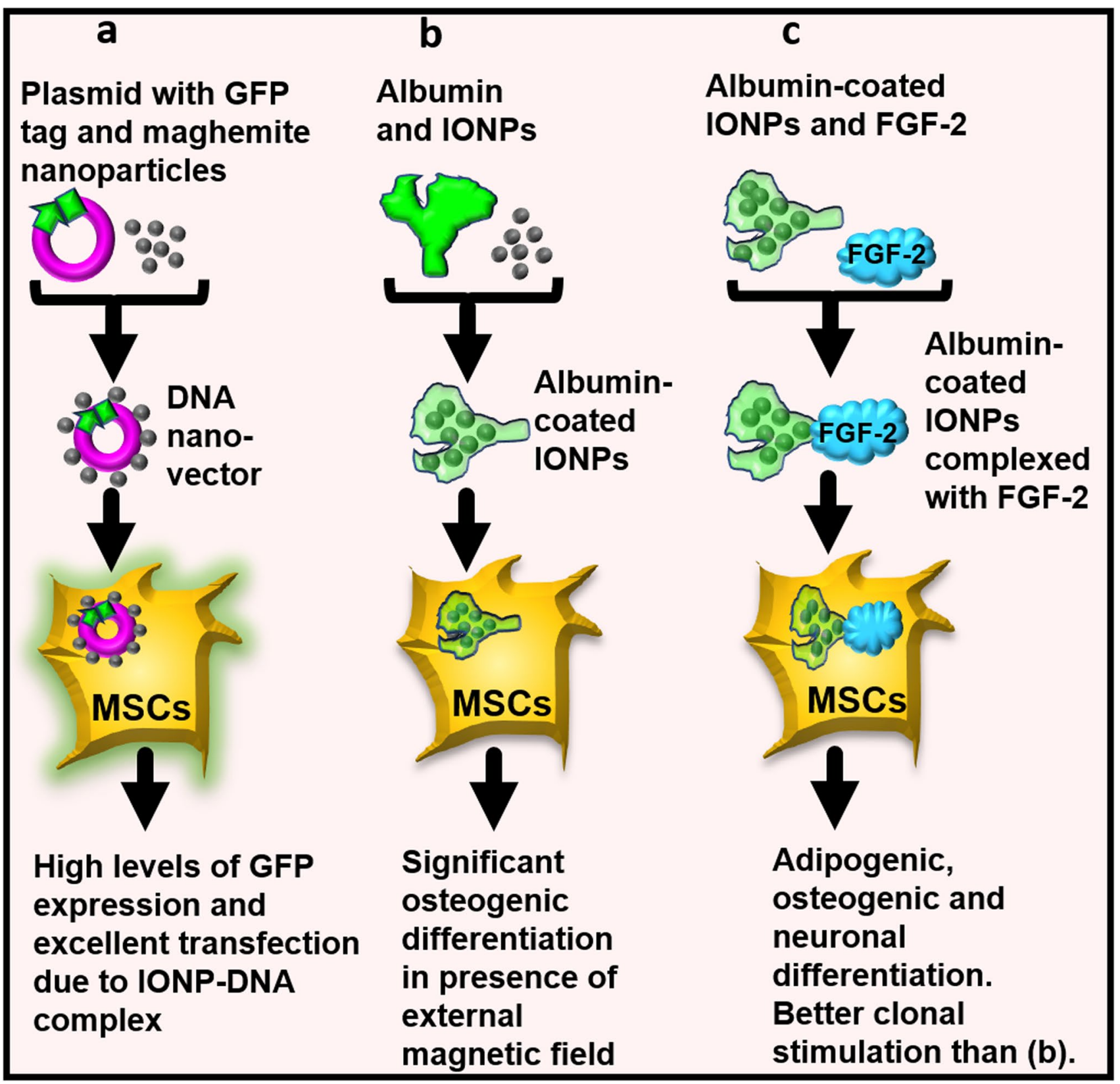

Fig. 4 Principle of labelling MSCs with iron oxide nanoparticles (IONPs) bound to DNA, albumin, and Fibroblast growth factor-2 (FGF-2). Schematic showing (a) IONPs bound to plasmid DNA,

BM-MSCs and these stimulated significant MSC osteogenic differentiation under a constant static magnetic field (Fig. 4b). This was indicated by increments in ALP activity and calcium deposition, along with elevations in the mRNA and protein expressions of osteocalcin and collagen I (Fig. 2) [123]. The complex of albumin and IONPs can bind to various macromolecules with high affinity. Levey et al. exploited this property. They conjugated albumin-coated IONPs to FGF-2 and observed the effect of this complex on human BM-MSCs in-vitro. (b) IONPs bound to albumin and (c) albumin-coated IONPs bound to FGF-2. Consequences of endocytosis of these complexes by the MSCs have been stated

Data showed that following endocytosis, the presence of FGF-2 enhanced MSC proliferation and promoted differentiation into adipogenic, osteogenic and neuronal lineages (Fig. 4c). Conjugated FGF-2 was able to better stimulate MSC clonal expansion than free growth factor, likely because it was stabilised against the action of enzymes and inhibitors in the serum and tissue culture [40]. These results help envisage wide biomedical applications of such complexes and better in-vivo detection of MSCs via MRI. 


\section{IONPs Complexed with Drug}

Human triple negative breast cancer is the most aggressive type of breast cancer. Doxorubicin is one of the recommended drugs to treat breast cancer. In dealing with cancer, there are issues such as drug-induced resistance, therapeutic inefficacy to tumours, systemic toxicity and lack of a system that allows regulated drug release to tumorous tissues. To overcome some of these issues, complexes including a combination of IONPs and dugs have been designed. A combination of lipids, doxorubicin (drug), gold nanorods and IONPs form a complex called LDGI. MSCs were successfully labelled with LDGI for photoacoustic imaging, targeted photothermal therapy and chemotherapy in mice models of breast cancer, aiming to apply this targeted therapy to human breast cancer. Invitro, the label was successfully taken up by the MSCs and did not alter cellular functions. Labelled MSCs maintained tumour tropism and the IONPs in the LDGI complex were found to upregulate CXCR4 on the MSCs (Fig. 2) [124]. In vivo, the complex provided a means of releasing the drug doxorubicin to promote cell apoptosis (via chemotherapy) and allow photothermal therapy simultaneously upon light irradiation. The MSC-LDGI complex was the most efficient in inhibiting tumour growth [124], which promised a clinically translatable drug delivery system via the MSCs.

Cell-membrane-coated nanoparticles show diagnostic and therapeutic applications. Recently, doxorubicin-loaded IONPs were coated with MSC membranes, and the therapeutic efficacy of this complex in treating colon cancer was examined in-vitro and in mice models. The complex showed better uptake by tumour cells, anti-tumour properties and reduced side-effects compared to the complex without MSC membranes [125]. This promised an excellent strategy for targeting tumours with specific systems that can deliver therapeutic drugs.

\section{Specific Caveats Associated with IONP-Labelling of MSCs}

Difficulties related to MSC labelling with IONPs and MSC detection, and possible solutions have been tabulated in Table 3. The list is not exhaustive.

In addition to the caveats discussed so far, IONP-labelling of MSCs poses challenges like decrement in cellular iron content upon cell proliferation, which leads to progressive loss of detection signal, expulsion of IONPs from labelled cells, engulfment of transplanted cells by macrophages resulting in false positives and an inability to detect cell differentiation $[27,36]$. In-vitro, cell division can cause the dilution effect and lead to progressive decline in labelling with increasing culture time [35]. For example, citrate-coated-IONP-labelled adipose-derived stem cells retained their ability of multilineage differentiation in-vitro, but the percent of labelled cells decreased during the 4-week in-vitro expansion [38]. Collectively, this makes long-term tracing difficult and may not reflect the true number of transplanted cells.

IONP concentration can determine MSC proliferation and differentiation ability. For example, although IONPlabelled umbilical cord MSCs could be successfully tracked in rat brains, labelling these MSCs with $100 \mu \mathrm{g} / \mathrm{mL}$ IONP decreased proliferation and influenced their differentiation ability into cartilage in-vitro [134]. Moreover, IONP uptake by MSCs is IONP-size dependent. For example, human foetal MSCs labelled with 600-nm microgel iron oxide particles (amongst a range sizes) showed 3-6-fold higher iron-loading than Ferucarbotran without affecting MSC proliferation or tri-lineage differentiation. In a rat photothrombotic stroke model, labelled MSCs successfully migrated from contralateral cortex to the site of stroke injury and showed 5-7 times higher MRI sensitivity than detection by Ferucarbotran. Also, it showed low cell toxicity, thus making this approach useful for tracking MSCs using clinical MRI scanners. However, due to necrosis and inflammation in the rat models, the transplanted human MSCs could not survive beyond 12 days [135]. Determination of long-term effects is pending.

IONPs are composed of iron, so these may generate ROS due to IONP-derived iron feeding into Fenton reaction. Due to their perinuclear localisation, IONPs can get access to cell transcription components and may alter gene expression directly. Also, IONP-entry-induced ROS may alter cell signalling pathways. While some of these changes can be beneficial (Fig. 2), these could also lead to toxic effects including morphological modifications, activation of immune responses and upregulation of redox-sensitive transcription factors [27]. Researchers have addressed some of these issues concerning IONP-labelling of MSCs and have proposed ways of tackling these challenges (Table 3).

\section{Impact of Similarity/Dissimilarly between MSCs from Different Sources on IONP-Labelling and its Outcomes}

MSCs can be sourced from various body tissues. It is important to address whether there is biological similarity between MSCs obtained from these different sources. All MSCs show similar phenotypic properties and possess fibroblast-like morphology. However, there are some differences. For example, although adipose-tissue-derived MSCs and BM-MSCs share several biological features, there are 


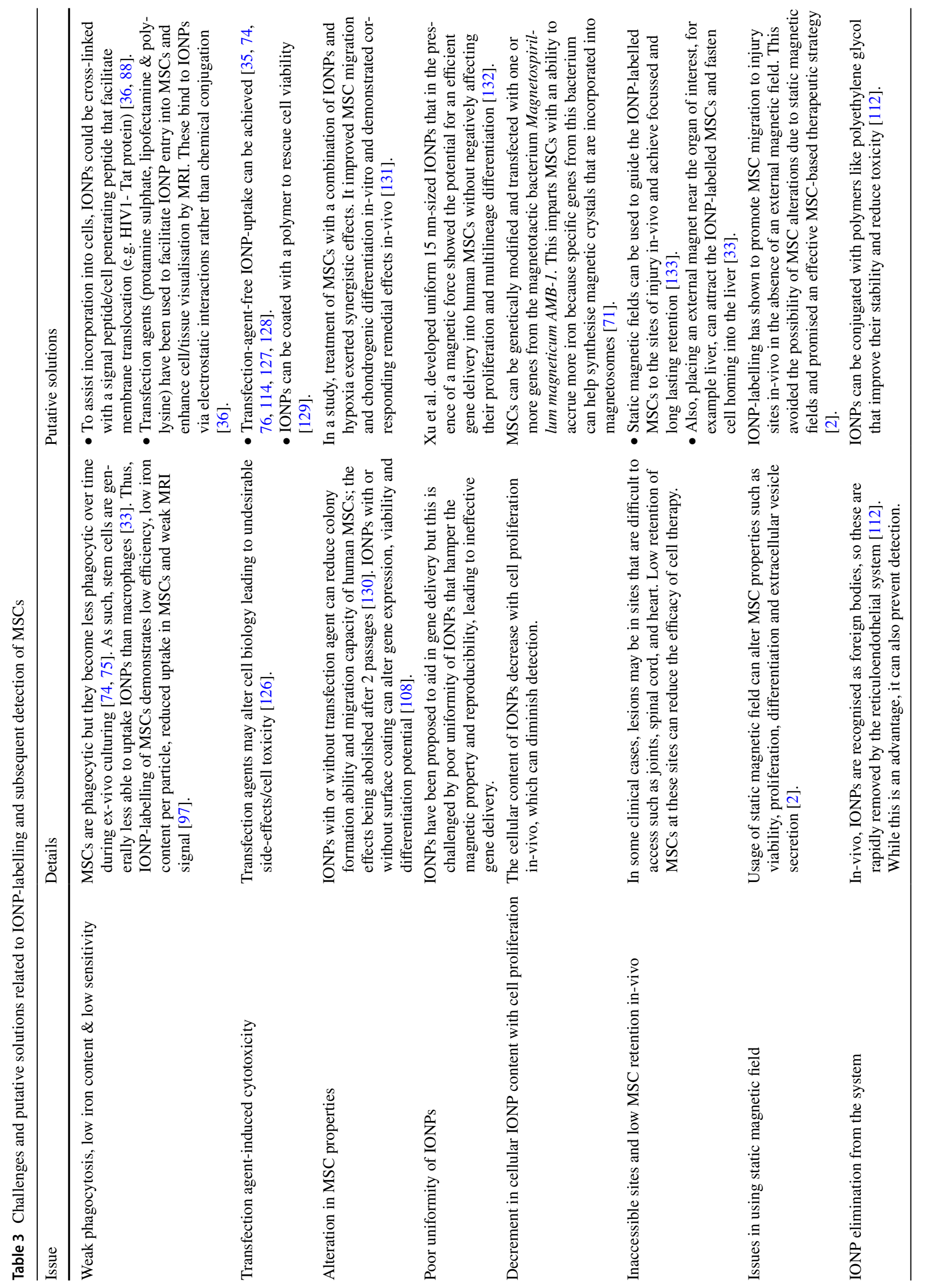


some minor differences in their transcriptomes and proteomes (as expected), immunomodulatory activities and differentiation potential [136]. Contextually, BM-MSCs show better osteogenic and chondrogenic potential than adipose-tissue-derived MSCs. The latter cells demonstrate better adipogenic capacity $[137,138]$ and better retention of trilineage differentiation capacity over time than BM-MSCs [139]. Note that these cell populations are heterogenous and therefore do not constitute a single cell type [3]. This may be an additional reason for the subtle differences. While both are suitable for clinical applications, MSCs from one source might be more suitable than MSCs from another source for a particular clinical application. For example, despite the ability of adipose-tissue-derived MSCs to regenerate bone, BM-MSCs would be more suitable for applications related to bone regeneration because of their higher potential to serve the purpose [140].

There are other examples that show some similarities and differences in MSCs from different sources. For example, MSCs from dental-pulp and umbilical cord have shown higher proliferation than BM-MSCs and adipose-tissue derived MSCs. In the context of pluripotency, dental-pulp MSCs have shown slightly different gene expression profile (relative gene expression) from the MSCs of bone marrow, adipose tissue, and umbilical cord, while the latter three MSCs have shown similarity in this aspect. Thus, dentalpulp MSCs showcase their neural crest origin and differ slightly from the MSCs of these three sources [141]. BMMSCs and neural stem cells are similar in their migration capacity and tropism for brain tumours [142, 143]. Also, both BM-MSCs and adipose-tissue-derived MSCs show pericyte-like characteristics and show similar tumour migration abilities. Thus, either could be used for targeting glioma [144]. Dental-pulp MSCs showed a more robust ability for osteogenic differentiation than adipose-tissue-derived MSCs [67]. Thus, the desired clinical outcome can better guide the choice/source of MSCs to be used.

Yet another interesting question is whether iron labelling works equally well for MSCs derived from different sources. This depends on the parameter being assessed and the MSCs being compared. For instance, in an in-vitro study, both adipose-tissue-derived MSCs and BM-MSCs could be IONP-labelled and then tracked with equal ease. Their responses to IONP-labelling were similar; both showed decrements in differentiation potential (adipogenic and osteogenic) following IONP-labelling, an increment in iron content, and a decrement in cell viability with increasing concentration of IONPs [145]. Another in-vitro study compared IONP-labelled MSCs from adipose tissue and Wharton's jelly. Here, IONP-labelled adipose-tissue-derived MSCs showed better proliferation and lower senescence than unlabelled counterparts and Wharton's jelly MSCs. IONPlabelled Wharton's jelly MSCs showed reduced viability in comparison to unlabelled Wharton's jelly MSCs. But this was not the case with adipose-tissue-derived MSCs. Also, IONP-labelling and magnetic field exposure promoted chondrogenesis in human adipose-tissue-derived MSCs but not in Wharton jelly MSCs [146]. Essentially, the chondrogenic potential of MSCs obtained from one source could be enhanced with magnetic stimulation but this did not occur in the MSCs from another source. Based on this data, adiposetissue-derived MSCs would be more suitable than Wharton's jelly MSCs for cartilage engineering. This clearly indicates that the source of MSCs determines its potential therapeutic usage, and IONP-labelling may (or may not) have differential effects on MSCs from different sources; conclusion on the latter will depend on the parameter being examined.

\section{Summary}

Prior to administration, MSCs are often labelled with contrast agents to facilitate post-transplantation detection via MRI. MSCs can be labelled with IONPs that act as good MRI contrast agents that improve the detection and tracking of administered MSCs and in some cases enhance MSC therapeutic potential and augment regenerative medicine. For labelling, IONPs can be complexed with carbohydrates, non-carbohydrate polymers, elements, compounds, stains, drugs, growth factors and DNA; the latter in combination with IONPs acts as a DNA nano-vector. The advantages, limitations, and applicability of these approaches, as discussed here, need to be considered appropriately before embarking on further MSC-related clinical trials.

\section{Current State, Hurdles, Future Work, and Perspectives}

There are several human studies wherein MSC therapy has shown success. For example, in clinical trials on graft-versushost-disease [147-149], osteoarthritis [150-152] multiple sclerosis [153], pulmonary diseases [154-156] and inflammatory bowel disease $[157,158]$. When Wharton's jelly MSCs were used to ameliorate acute myocardial infarction, gadolinium-enhanced cardiac MRI, echocardiography, and ECG-gated single photon emission computed tomography were used. The approach was found to be safe and effective [159]. In all these studies, the focus was on directly examining the primary and secondary clinical outcomes post transplantation rather than detecting the location, survival, and differentiation of MSCs at the target site and then relating this to the clinical outcome. Indeed, MRI was used in some studies, but this was to examine alteration, regression, or amelioration of the condition/tissue following treatment. Success achieved in these studies (in terms of achieving the 
desired clinical outcomes) implied MSC-treatment efficacy and appropriate MSC functionality at the target site.

The aim of cell therapy is to regenerate/rejuvenate the damaged tissue so that the original tissue function is restored without causing cytotoxicity or inducing any aberrant processes including tumour formation. The latter is a major concern when using stem cells. The tumour forming ability is primarily due to their ability to proliferate for a long time and resist apoptosis. However, this is dependent on several factors such as donor's age, patient's health and MSC reaction at the target site. One approach to tackle this is to use MSC extracellular vesicles instead of whole cells. These vesicles contain therapeutic paracrine factors including mRNA, DNA and growth factors and have been found to mediate repair [23].

Regardless, the remarkable ability of MSCs (and stem cells in general) to differentiate into multiple cell types accompanied by advantages such as ease of isolation and expansion in-vitro, and the ability to extract these cells from multiple sources collectively make these cells lucrative options for therapeutic applications. MSCs are considered safe to use, but continuous follow-up studies through preclinical and clinical trials are necessary to ascertain this. Setting up more pre-clinical trials in small animals would be one step forward. Another step would be to use CRISPR/ Cas9 technology for gene editing. The usage of this technology has shown promising results in various degenerative diseases [160] and can now be more frequently applied than before in pre-clinical trials. In the past, a large proportion of MSC studies focussed on and explored their osteogenic, chondrogenic and adipogenic potential aiming to ameliorate various conditions. Success has been achieved with this, for example, in ameliorating knee osteoarthritis and spinal cord injury. In recent years, the usage of MSCs in cancer therapy, particularly as a means of drug delivery has emerged and this approach has shown promising results in animal models [161-166].

\section{Generic Issues with Post-Transplant Cell Tracking}

There are some generic problems associated with post-transplantation tracking following cell-based therapies. Utilising histopathology might be the gold standard for preclinical studies involving small animals, but it is labour intensive, time-consuming, and prone to errors and bias. For studies in humans, biopsy-driven tissue histopathology is neither always possible nor advisable or necessary, particularly, with the advent of non-invasive approaches that show successful in-vivo cell imaging. Another issue relates to the imaging approach itself. There are several imaging modalities that facilitate in-vivo imaging, for example, MRI, bioluminescence imaging, reporter gene labelling via fluorescence, fluorescent dyes, ultrasound, quantum dots and single-photon emission computed tomography (SPECT) and positron emission tomography (PET). However, all these present some limitations. For example, PET and MRI are more expensive than others and there is variability in sensitivity [167]. There are challenges in using the methods used too. Cells can be difficult to track with optical imaging if there has been direct labelling with fluorescent probes because the signal decreases in the tissue with time. It is even more challenging when the tissue is located deep within the body. Thus, long-term cell monitoring can be difficult. Radionuclides are high-energy particles that are less prone to attenuation in tissues. A combination of radionuclide-labelling and PET imaging is often used in clinical settings, but it can detect both dead and live cells giving an incorrect account of viable cells. MRI certainly offers an advantage by allowing MSC visualisation immediately after transplantation but there are issues such as signal dilution over time and the signal may not necessarily match with cell viability of transplanted cells due to non-specific particle uptake and signal retention by dead cells [168].

\section{MSC-Related Issues with Post-Transplant Cell Tracking}

Some studies have shown issues related to labelling and tracking of MSCs. For example, MSC labelling with silicacoated gold nanorods impacted their cytokine profile [169] and MSC labelling with radioisotopes reduced MSC metabolic activity and migration [170]. Labelling can be achieved by transfection with a reporter gene, but over time the gene may be silenced leading to reductions in signal and product of the reporter gene. This can be misinterpreted as cell death. Indeed, constitutive mammalian promoters (ubiquitin and $\beta$-actin) are being utilised because these are believed to be more resistant to gene silencing. This approach has shown success [171]. However, there are concerns over reporter genes being integrated at random sites in the genome and this may alter MSC characteristics. Again, the aim is to counteract this by using editing technologies that allow sitespecific DNA integration [168].

\section{The Concept of IONP-Labelling}

Iron labelling of cells enables the usage of non-invasive MRI for cell detection and tracking, which imparts a huge advantage. Moreover, IONPs offer advantage over gadolinium in that iron is naturally present in the human body (about $3-4 \mathrm{~g}$ in an adult). With IONP-based MRI tracking, the dose is about $10 \mathrm{mg}$ [25]. In theory, the body should be able to accommodate this subtle level of change in iron levels without causing major undesirable physiological outcomes. Iron oxide labelling of neural stem cells do cause alterations in the expression of some genes, including some iron-related 
genes [172] but these are believed to be temporary. Whether these alterations occur in humans too, and if so, whether these are temporary or permanent, needs to be investigated.

As in January 2022, a total of less than twenty clinical trials under 'iron oxide nanoparticle' are found on Clinical Trials Registers for Europe and US. While the first-generation IONPs like ferumoxide (Feridex and/or Endorem) and ferucarbotran (Resovist) are not used anymore in clinical applications in US and Europe, some of the currently registered trials use the 2nd generation of IONPs like ferumoxytol (Feraheme) and ferumoxtran-10. Since these do not show a great ability to be internalised by the cells, transfection agents are being used to achieve better cellular uptake. But usage of transfection agent is not problem-free (Table 3). Characteristic issues with its usage are nanoparticle precipitation due to mixing of negatively charged iron-oxides with positively charged transfection agent, and the need to use serum-free media to maximise the association between transfection agent and nanoparticles. However serum-free media cannot be used with all cells [25]. To tackle this, transfection agent-free approaches have been developed (Table 3).

Nevertheless, several studies have shown success in posttransplant monitoring of IONP-labelled cells in humans. For example, systemic delivery of IONP-labelled peripheral blood mononuclear cells was found to be safe. Healthy recipients showed no significant alterations in blood chemistry and cardiovascular physiology. The labelling did not alter cellular cytokine profile, migration, and homing, and the labelled cells were detectable via MRI for at least one week [173]. Also, IONP-labelling followed by MRI-based detection has been able to track transplanted cells in the spinal cord, occipital horns of multiple sclerosis patients and the brain of a child with ischemic brain injury [25].

\section{IONP-Labelling of MSCs}

In the context of using IONPs on MSCs, some studies have shown inhibition of chondrogenic differentiation of MSCs following IONP-labelling (Feridex or Reovist) $[174,175]$. Whether this would occur in humans needs to be investigated. One way to investigate the effect of IONP loading on MSCs is to ascertain endogenous ferritin levels in MSCs from different sources and determine the range of ferritin increment following IONP-labelling. This is particularly relevant when using iron oxide for labelling MSCs. While iron is necessary for cellular functions, excess iron is toxic and can feed into the Fenton reaction to generate reactive oxygen species. If in excess, these can cause cellular damage. Ferritin is the iron storage protein that can accommodate large amounts of iron ions and thereby reduce the possibility of excess-iron-induced damage. Examining the basal and IONP-induced ferritin levels in MSCs from different sources would better inform the IONP dosage to be used. Optimal IONP dosage would prevent excess-iron-induced damage to MSCs and help retain MSC viability and characteristics so that the cells function optimally following transplantation. This needs to be tested for MSCs from all sources because their ironholding capacities may differ.

Generic concerns of cell-based therapy remain. These fundamentally relate to obtaining enough cells for transplantation, retaining their functional characteristics during in-vitro expansion, cell delivery to the target organ without viral or prion transmission, viability, differentiation, and functionality of cells upon reaching the target organ, immune response due to allogenic cell transplants, and carcinogenesis at the injection site. Questions that are yet to be answered include whether these cell-based therapies can improve the clinical outcome of all patients, whether this approach is applicable to all conditions, if yes, then to what extent, and if no, then to which conditions is the approach most and least applicable.

Abbreviations ALP: Alkaline phosphatase; BM-MSCs: Bone marrowderived mesenchymal stem cells; BMP: Bone morphogenetic protein; CCL21: C-C motif ligand-21; CCR: C-C motif chemokine receptor; CXCR: C-X-C motif chemokine receptor; EGF: Epidermal growth factor; EGFR: Epidermal growth factor receptor; FGF-2: Fibroblast growth factor-2; GFP: Green fluorescent protein; HGF: Hepatocyte growth factor; HIF1- $\alpha$ : Hypoxia inducible factor 1 alpha; IL: Interleukin; IONPs: Iron-oxide nanoparticles; MCP-1: Monocyte chemoattractant protein-1; MRI: Magnetic resonance imaging; MSCs: Mesenchymal stem cells; PPAR $\gamma$ : Peroxisome proliferator-activated receptor gamma; SDF-1: Stromal cell-derived factor-1; SPIONPs: superparamagnetic iron oxide nanoparticles; TGF- $\beta$ : Transforming growth factor beta; TNF- $\alpha$ : Tumour necrosis factor alpha; USSPIONP: Ultrasmall superparamagnetic iron oxide nanoparticles; VEGF: Vascular endothelial growth factor; $\alpha \mathrm{SMA}$ : alpha smooth muscle actin

Acknowledgements This article is made open access with the financial support of King's College London, UK.

Authors' Contributions Conceptualisation, composition, and writing: Kosha J. Mehta.

Data Availability Not applicable.

Code Availability Not applicable.

\section{Declarations}

Ethics Approval Not applicable.

Consent to Participate Not applicable.

Consent for Publication Not applicable.

Conflict of Interest The author declares no conflict of interest. 
Open Access This article is licensed under a Creative Commons Attribution 4.0 International License, which permits use, sharing, adaptation, distribution and reproduction in any medium or format, as long as you give appropriate credit to the original author(s) and the source, provide a link to the Creative Commons licence, and indicate if changes were made. The images or other third party material in this article are included in the article's Creative Commons licence, unless indicated otherwise in a credit line to the material. If material is not included in the article's Creative Commons licence and your intended use is not permitted by statutory regulation or exceeds the permitted use, you will need to obtain permission directly from the copyright holder. To view a copy of this licence, visit http://creativecommons.org/licenses/by/4.0/.

\section{References}

1. Kidd, S., Spaeth, E., Dembinski, J. L., Dietrich, M., Watson, K., Klopp, A., ... Marini, F. C. (2009). Direct evidence of mesenchymal stem cell tropism for tumor and wounding microenvironments using in vivo bioluminescent imaging. Stem Cells (Dayton, Ohio), 27(10), 2614-2623. https://doi.org/10.1002/stem.187

2. Li, X., Wei, Z., Lv, H., Wu, L., Cui, Y., Yao, H., ... Jiang, J. (2019). Iron oxide nanoparticles promote the migration of mesenchymal stem cells to injury sites. International Journal of Nanomedicine, 14, 573-589. https://doi.org/10.2147/IJN.S1849 20

3. Mehta, K. J. (2021). Role of iron and iron-related proteins in mesenchymal stem cells: Cellular and clinical aspects. Journal of Cellular Physiology. https://doi.org/10.1002/jcp.30383

4. Blondiaux, E., Pidial, L., Autret, G., Rahmi, G., Balvay, D., Audureau, E., ... Clément, O. (2017). Bone marrow-derived mesenchymal stem cell-loaded fibrin patches act as a reservoir of paracrine factors in chronic myocardial infarction. Journal of Tissue Engineering and Regenerative Medicine, 11(12), 3417-3427. https://doi.org/10.1002/term.2255

5. Chung, T.-H., Hsu, S.-C., Wu, S.-H., Hsiao, J.-K., Lin, C.-P., Yao, M., \& Huang, D.-M. (2018). Dextran-coated iron oxide nanoparticle-improved therapeutic effects of human mesenchymal stem cells in a mouse model of Parkinson's disease. Nanoscale, 10(6), 2998-3007. https://doi.org/10.1039/c7nr06976f

6. Pittenger, M. F., Discher, D. E., Péault, B. M., Phinney, D. G., Hare, J. M., \& Caplan, A. I. (2019). Mesenchymal stem cell perspective: Cell biology to clinical progress. Npj. Regenerative Medicine, 4(1), 1-15. https://doi.org/10.1038/ s41536-019-0083-6

7. Emadedin, M., Labibzadeh, N., Liastani, M. G., Karimi, A., Jaroughi, N., Bolurieh, T., ... Aghdami, N. (2018). Intra-articular implantation of autologous bone marrow-derived mesenchymal stromal cells to treat knee osteoarthritis: A randomized, tripleblind, placebo-controlled phase 1/2 clinical trial. Cytotherapy, 20(10), 1238-1246. https://doi.org/10.1016/j.jcyt.2018.08.005

8. Garza, J. R., Campbell, R. E., Tjoumakaris, F. P., Freedman, K. B., Miller, L. S., Santa Maria, D., \& Tucker, B. S. (2020). Clinical efficacy of intra-articular mesenchymal stromal cells for the treatment of knee osteoarthritis: A double-blinded prospective randomized controlled clinical trial. The American Journal of Sports Medicine, 48(3), 588-598. https://doi.org/10.1177/03635 46519899923

9. Karussis, D., Karageorgiou, C., Vaknin-Dembinsky, A., GowdaKurkalli, B., Gomori, J. M., Kassis, I., ... Slavin, S. (2010). Safety and immunological effects of mesenchymal stem cell transplantation in patients with multiple sclerosis and amyotrophic lateral sclerosis. Archives of Neurology, 67(10), 11871194. https://doi.org/10.1001/archneurol.2010.248
10. Yang, Y., Pang, M., Chen, Y.-Y., Zhang, L.-M., Liu, H., Tan, J., ... Rong, L.-M. (2020). Human umbilical cord mesenchymal stem cells to treat spinal cord injury in the early chronic phase: Study protocol for a prospective, multicenter, randomized, placebo-controlled, single-blinded clinical trial. Neural Regeneration Research, 15(8), 1532-1538. https://doi.org/10.4103/ 1673-5374.274347

11. Lee, R. H., Pulin, A. A., Seo, M. J., Kota, D. J., Ylostalo, J., Larson, B. L., ... Prockop, D. J. (2009). Intravenous hMSCs improve myocardial infarction in mice because cells embolized in lung are activated to secrete the anti-inflammatory protein TSG-6. Cell Stem Cell, 5(1), 54-63. https://doi.org/10.1016/j.stem.2009.05. 003

12. Yang, Y.-J., Qian, H.-Y., Huang, J., Geng, Y.-J., Gao, R.-L., Dou, K.-F., ... Zhao, S.-H. (2008). Atorvastatin treatment improves survival and effects of implanted mesenchymal stem cells in post-infarct swine hearts. European Heart Journal, 29(12), 1578-1590. https://doi.org/10.1093/eurheartj/ehn167

13. Zhang, J., Wu, Y., Chen, A., \& Zhao, Q. (2015). Mesenchymal stem cells promote cardiac muscle repair via enhanced neovascularization. Cellular Physiology and Biochemistry: International Journal of Experimental Cellular Physiology, Biochemistry, and Pharmacology, 35(3), 1219-1229. https://doi.org/10.1159/00037 3945

14. Bai, L., Lennon, D. P., Caplan, A. I., DeChant, A., Hecker, J., Kranso, J., ... Miller, R. H. (2012). Hepatocyte growth factor mediates mesenchymal stem cell-induced recovery in multiple sclerosis models. Nature Neuroscience, 15(6), 862-870. https:// doi.org/10.1038/nn.3109

15. Xu, L., Yuan, S., Chen, W., Ma, Y., Luo, Y., Guo, W., \& Yang, S. (2020). Transplantation and tracking of the human umbilical cord mesenchymal stem cell labeled with superparamagnetic Iron oxide in deaf pigs. Anatomical Record (Hoboken, N.J.: 2007), 303(3), 494-505. https://doi.org/10.1002/ar.24346

16. Cancedda, R., Giannoni, P., \& Mastrogiacomo, M. (2007). A tissue engineering approach to bone repair in large animal models and in clinical practice. Biomaterials, 28(29), 4240-4250. https:// doi.org/10.1016/j.biomaterials.2007.06.023

17. Atluri, S., Manchikanti, L., \& Hirsch, J. A. (2020). Expanded umbilical cord mesenchymal stem cells (UC-MSCs) as a therapeutic strategy in managing critically ill COVID-19 patients: The case for compassionate use. Pain Physician, 23(2), E71-E83.

18. Durand, N., Mallea, J., \& Zubair, A. C. (2020). Insights into the use of mesenchymal stem cells in COVID-19 mediated acute respiratory failure. Npj Regenerative Medicine, 5(1), 1-9. https:// doi.org/10.1038/s41536-020-00105-z

19. Canham, M. A., Campbell, J. D. M., \& Mountford, J. C. (2020). The use of mesenchymal stromal cells in the treatment of coronavirus disease 2019. Journal of Translational Medicine, 18(1), 359. https://doi.org/10.1186/s12967-020-02532-4

20. Wang, S. H., Shetty, A. K., Jin, K., \& Chunhua Zhao, R. (2021). Combating COVID-19 with mesenchymal stem/stromal cell therapy: Promise and challenges. Frontiers in Cell and Developmental Biology, 8. https://doi.org/10.3389/fcell.2020.627414

21. Mastrolia, I., Foppiani, E. M., Murgia, A., Candini, O., Samarelli, A. V., Grisendi, G., ... Dominici, M. (2019). Challenges in clinical development of mesenchymal stromal/stem cells: Concise review. Stem Cells Translational Medicine, 8(11), 1135-1148. https://doi.org/10.1002/sctm.19-0044

22. Lukomska, B., Stanaszek, L., Zuba-Surma, E., Legosz, P., Sarzynska, S., \& Drela, K. (2019). Challenges and controversies in human mesenchymal stem cell therapy. Stem Cells International, 2019. https://doi.org/10.1155/2019/9628536

23. Musiał-Wysocka, A., Kot, M., \& Majka, M. (2019). The pros and cons of mesenchymal stem cell-based therapies. Cell 
Transplantation, 28(7), 801-812. https://doi.org/10.1177/09636 89719837897

24. Wahsner, J., Gale, E. M., Rodríguez-Rodríguez, A., \& Caravan, P. (2019). Chemistry of MRI contrast agents: Current challenges and new Frontiers. Chemical Reviews, 119(2), 957-1057. https:// doi.org/10.1021/acs.chemrev.8b00363

25. Bulte, J. W. M., \& Daldrup-Link, H. E. (2018). Clinical tracking of cell transfer and cell transplantation: Trials and tribulations. Radiology, 289(3), 604-615. https://doi.org/10.1148/radiol. 2018180449

26. Yim, H., Seo, S., \& Na, K. (2011). MRI contrast agent-based multifunctional materials: Diagnosis and therapy. Journal of Nanomaterials, 2011, e747196. https://doi.org/10.1155/2011/ 747196

27. Accomasso, L., Gallina, C., Turinetto, V., \& Giachino, C. (2015). Stem cell tracking with nanoparticles for regenerative medicine purposes: An overview. Stem Cells International, 2016, 7920358. https://doi.org/10.1155/2016/7920358

28. Schäfer, R., Kehlbach, R., Wiskirchen, J., Bantleon, R., Pintaske, J., Brehm, B. R., ... Northoff, H. (2007). Transferrin receptor upregulation: In vitro labeling of rat mesenchymal stem cells with superparamagnetic iron oxide. Radiology, 244(2), 514-523. https://doi.org/10.1148/radiol.2442060599

29. Rosenberg, J. T., Yuan, X., Grant, S., \& Ma, T. (2016). Tracking mesenchymal stem cells using magnetic resonance imaging. Brain Circulation, 2(3), 108-113. https://doi.org/10.4103/23948108.192521

30. Harrison, R. P., Chauhan, V. M., Onion, D., Aylott, J. W., \& Sottile, V. (2019). Intracellular processing of silica-coated superparamagnetic iron nanoparticles in human mesenchymal stem cells. RSC Advances, 9(6), 3176-3184. https://doi.org/10.1039/ c8ra09089k

31. Hankins, J. S., McCarville, M. B., Loeffler, R. B., Smeltzer, M. P., Onciu, M., Hoffer, F. A., ... Hillenbrand, C. M. (2009). R2* magnetic resonance imaging of the liver in patients with iron overload. Blood, 113(20), 4853-4855. https://doi.org/10.1182/ blood-2008-12-191643

32. Wood, J. C., Enriquez, C., Ghugre, N., Tyzka, J. M., Carson, S., Nelson, M. D., \& Coates, T. D. (2005). MRI R2 and R2* mapping accurately estimates hepatic iron concentration in transfusion-dependent thalassemia and sickle cell disease patients. Blood, 106(4), 1460-1465. https://doi.org/10.1182/ blood-2004-10-3982

33. Pastor, C. M. (2005). Tracking mesenchymal stem cells in the liver by magnetic resonance imaging. Journal of Hepatology, 43(5), 915-916. https://doi.org/10.1016/j.jhep.2005.07.021

34. Daldrup-Link, H. E. (2017). Ten things you might not know about Iron oxide nanoparticles. Radiology, 284(3), 616-629. https://doi.org/10.1148/radiol.2017162759

35. Harrison, R., Markides, H., Morris, R. H., Richards, P., El Haj, A. J., \& Sottile, V. (2017). Autonomous magnetic labelling of functional mesenchymal stem cells for improved traceability and spatial control in cell therapy applications. Journal of Tissue Engineering and Regenerative Medicine, 11(8), 2333-2348. https://doi.org/10.1002/term.2133

36. Kircher, M. F., Gambhir, S. S., \& Grimm, J. (2011). Noninvasive cell-tracking methods. Nature reviews. Clinical Oncology, 8(11), 677-688. https://doi.org/10.1038/nrclinonc.2011.141

37. Rajan, A., Sharma, M., \& Sahu, N. K. (2020). Assessing magnetic and inductive thermal properties of various surfactants functionalised $\mathrm{Fe} 3 \mathrm{O} 4$ nanoparticles for hyperthermia. Scientific Reports, 10(1), 15045. https://doi.org/10.1038/ s41598-020-71703-6

38. Radeloff, K., Radeloff, A., Ramos Tirado, M., Scherzad, A., Hagen, R., Kleinsasser, N. H., \& Hackenberg, S. (2020). Toxicity and functional impairment in human adipose tissue-derived stromal cells (hASCs) following long-term exposure to very small Iron oxide particles (VSOPs). Nanomaterials (Basel, Switzerland), 10(4). https://doi.org/10.3390/nano10040741

39. Ventola, C. L. (2012). The nanomedicine revolution: Part 1: Emerging concepts. P \& T: A Peer-Reviewed Journal for Formulary Management, 37(9), 512-525.

40. Levy, I., Sher, I., Corem-Salkmon, E., Ziv-Polat, O., Meir, A., Treves, A. J., ... Rotenstreich, Y. (2015). Bioactive magnetic near infra-red fluorescent core-shell iron oxide/human serum albumin nanoparticles for controlled release of growth factors for augmentation of human mesenchymal stem cell growth and differentiation. Journal of Nanobiotechnology, 13, 34. https:// doi.org/10.1186/s12951-015-0090-8

41. Mohanty, S., Jain, K. G., Nandy, S. B., Kakkar, A., Kumar, M., Dinda, A. K., ... Ray, A. (2018). Iron oxide labeling does not affect differentiation potential of human bone marrow mesenchymal stem cells exhibited by their differentiation into cardiac and neuronal cells. Molecular and Cellular Biochemistry, 448(1), 17-26. https://doi.org/10.1007/s11010-018-3309-9

42. von Bahr, L., Batsis, I., Moll, G., Hägg, M., Szakos, A., Sundberg, B., ... Le Blanc, K. (2012). Analysis of tissues following mesenchymal stromal cell therapy in humans indicates limited long-term engraftment and no ectopic tissue formation. Stem Cells (Dayton, Ohio), 30(7), 1575-1578. https://doi.org/10.1002/ stem. 1118

43. Hsieh, C.-C., Hsu, S.-C., Yao, M., \& Huang, D.-M. (2021). CD9 upregulation-decreased CCL21 secretion in mesenchymal stem cells reduces Cancer cell migration. International Journal of Molecular Sciences, 22(4). https://doi.org/10.3390/ijms220417 38

44. Wang, Q., Chen, B., Cao, M., Sun, J., Wu, H., Zhao, P., ... Gu, N. (2016). Response of MAPK pathway to iron oxide nanoparticles in vitro treatment promotes osteogenic differentiation of $\mathrm{hBM}$ SCs. Biomaterials, 86, 11-20. https://doi.org/10.1016/j.bioma terials.2016.02.004

45. Lin, T., Kohno, Y., Huang, J.-F., Romero-Lopez, M., Pajarinen, J., Maruyama, M., ... Goodman, S. B. (2018). NFкB sensing IL-4 secreting mesenchymal stem cells mitigate the Proinflammatory response of macrophages exposed to polyethylene Wear particles. Journal of Biomedical Materials Research. Part A, 106(10), 2744-2752. https://doi.org/10.1002/jbm.a.36504

46. Labusca, L., Herea, D.-D., Danceanu, C.-M., Minuti, A. E., Stavila, C., Grigoras, M., ... Lupu, N. (2020). The effect of magnetic field exposure on differentiation of magnetite nanoparticleloaded adipose-derived stem cells. Materials Science \& Engineering. C, Materials for Biological Applications, 109, 110652. https://doi.org/10.1016/j.msec.2020.110652

47. Ruppert, K. A., Prabhakara, K. S., Toledano-Furman, N. E., Udtha, S., Arceneaux, A. Q., Park, H., ... Olson, S. D. (2020). Human adipose-derived mesenchymal stem cells for acute and sub-acute TBI. PLoS One, 15(5), e0233263. https://doi.org/10. 1371/journal.pone.0233263

48. Castro-Oropeza, R., Vazquez-Santillan, K., Díaz-Gastelum, C., Melendez-Zajgla, J., Zampedri, C., Ferat-Osorio, E., ... Maldonado, V. (2020). Adipose-derived mesenchymal stem cells promote the malignant phenotype of cervical cancer. Scientific Reports, 10(1), 14205. https://doi.org/10.1038/ s41598-020-69907-X

49. Qin, Y., Zhuo, L., Cai, J., He, X., Liu, B., Feng, C., \& Zhang, L. (2018). In vivo monitoring of magnetically labeled mesenchymal stem cells homing to rabbit hepatic VX2 tumors using magnetic resonance imaging. Molecular Medicine Reports, 17(1), 452458. https://doi.org/10.3892/mmr.2017.7902

50. Pavon, L. F., Sibov, T. T., de Souza, A. V., da Cruz, E. F., Malheiros, S. M. F., Cabral, F. R., ... Cavalheiro, S. (2018). Tropism of mesenchymal stem cell toward CD133+ stem cell of 
glioblastoma in vitro and promote tumor proliferation in vivo. Stem Cell Research \& Therapy, 9(1), 310. https://doi.org/10. 1186/s13287-018-1049-0

51. Chung, T.-H., Hsieh, C.-C., Hsiao, J.-K., Hsu, S.-C., Yao, M., \& Huang, D.-M. (2016). Dextran-coated iron oxide nanoparticles turn protumor mesenchymal stem cells (MSCs) into antitumor MSCs. RSC Advances, 6(51), 45553-45561. https://doi.org/10. 1039/C6RA03453E

52. Shi, M., Li, J., Liao, L., Chen, B., Li, B., Chen, L., ... Zhao, R. C. (2007). Regulation of CXCR4 expression in human mesenchymal stem cells by cytokine treatment: Role in homing efficiency in NOD/SCID mice. Haematologica, 92(7), 897-904. https://doi. org/10.3324/haematol.10669

53. Wynn, R. F., Hart, C. A., Corradi-Perini, C., O'Neill, L., Evans, C. A., Wraith, J. E., ... Bellantuono, I. (2004). A small proportion of mesenchymal stem cells strongly expresses functionally active CXCR4 receptor capable of promoting migration to bone marrow. Blood, 104(9), 2643-2645. https://doi.org/10.1182/ blood-2004-02-0526

54. Abdal Dayem, A., Hossain, M. K., Lee, S. B., Kim, K., Saha, S. K., Yang, G.-M., ... Cho, S.-G. (2017). The role of reactive oxygen species (ROS) in the biological activities of metallic nanoparticles. International Journal of Molecular Sciences, 18(1). https://doi.org/10.3390/ijms18010120

55. Yun, W. S., Choi, J. S., Ju, H. M., Kim, M. H., Choi, S. J., Oh, E. S., ... Key, J. (2018). Enhanced homing technique of mesenchymal stem cells using Iron oxide nanoparticles by magnetic attraction in olfactory-injured mouse models. International Journal of Molecular Sciences, 19(5). https://doi.org/10.3390/ijms190513 76

56. Huang, X., Zhang, F., Wang, Y., Sun, X., Choi, K. Y., Liu, D., ... Chen, X. (2014). Design considerations of Iron-based nanoclusters for noninvasive tracking of mesenchymal stem cell homing. ACS Nano, 8(5), 4403-4414. https://doi.org/10.1021/nn4062726

57. Li, X., Wei, Z., Li, B., Li, J., Lv, H., Wu, L., .. Jiang, J. (2019). In vivo migration of Fe3O4@polydopamine nanoparticle-labeled mesenchymal stem cells to burn injury sites and their therapeutic effects in a rat model. Biomaterials Science, 7(7), 2861-2872. https://doi.org/10.1039/c9bm00242a

58. Chung, T.-H., Hsiao, J.-K., Hsu, S.-C., Yao, M., Chen, Y.-C., Wang, S.-W., ... Huang, D.-M. (2011). Iron oxide nanoparticleinduced epidermal growth factor receptor expression in human stem cells for tumor therapy. ACS Nano, 5(12), 9807-9816. https://doi.org/10.1021/nn2033902

59. Kim, Y. H., Jung, E., Im, G.-B., Kim, Y.-J., Kim, S.-W., Jeong, G.-J., ... Bhang, S. H. (2020). Regulation of intracellular transition metal ion level with a $\mathrm{pH}$-sensitive inorganic nanocluster to improve therapeutic angiogenesis by enriching conditioned medium retrieved from human adipose derived stem cells. Nano Convergence, 7(1), 34. https://doi.org/10.1186/ s40580-020-00244-5

60. Ejtehadifar, M., Shamsasenjan, K., Movassaghpour, A., Akbarzadehlaleh, P., Dehdilani, N., Abbasi, P., ... Saleh, M. (2015). The effect of hypoxia on mesenchymal stem cell biology. Advanced Pharmaceutical Bulletin, 5(2), 141-149. https://doi.org/10. 15171/apb.2015.021

61. Im, G.-B., Jung, E., Kim, Y. H., Kim, Y.-J., Kim, S.-W., Jeong, G.-J., ... Bhang, S. H. (2020). Endosome-triggered ion-releasing nanoparticles as therapeutics to enhance the angiogenic efficacy of human mesenchymal stem cells. Journal of Controlled Release: Official Journal of the Controlled Release Society, 324, 586-597. https://doi.org/10.1016/j.jconrel.2020.05.038

62. Gomes, C. M. F. (2013). The dual role of mesenchymal stem cells in tumor progression. Stem Cell Research \& Therapy, 4(2), 42. https://doi.org/10.1186/scrt189
63. Liang, W., Chen, X., Zhang, S., Fang, J., Chen, M., Xu, Y., \& Chen, X. (2021). Mesenchymal stem cells as a double-edged sword in tumor growth: Focusing on MSC-derived cytokines. Cellular \& Molecular Biology Letters, 26(1), 3. https://doi.org/ 10.1186/s11658-020-00246-5

64. Chen, J., Ji, T., Wu, D., Jiang, S., Zhao, J., Lin, H., \& Cai, X. (2019). Human mesenchymal stem cells promote tumor growth via MAPK pathway and metastasis by epithelial mesenchymal transition and integrin $\alpha 5$ in hepatocellular carcinoma. Cell Death \& Disease, 10(6), 1-12. https://doi.org/10.1038/ s41419-019-1622-1

65. Mehta, K. J., \& Sharp, P. A. (2020). Iron elevates mesenchymal and metastatic biomarkers in HepG2 cells. Scientific Reports, 10. https://doi.org/10.1038/s41598-020-78348-5

66. Tangchitphisut, P., Srikaew, N., Phongkitkarun, S., Jaovisidha, S., \& Tawonsawatruk, T. (2020). Using iron sucrose-labeled adipose-derived mesenchymal stem cells in 1.5 and $3 \mathrm{~T}$ MRI tracking: An in vitro study. Heliyon, 6(8). https://doi.org/10. 1016/j.heliyon.2020.e04582

67. Altanerova, U., Benejova, K., Altanerova, V., Tyciakova, S., Rychly, B., Szomolanyi, P., ... Altaner, C. (2016). Dental pulp mesenchymal stem/stromal cells labeled with iron sucrose release exosomes and cells applied intra-nasally migrate to intracerebral glioblastoma. Neoplasma, 63(6), 925-933. https://doi.org/10. 4149/neo_2016_611

68. Papadimitriou, N., Thorfve, A., Brantsing, C., Junevik, K., Baranto, A., \& Barreto Henriksson, H. (2014). Cell viability and chondrogenic differentiation capability of human mesenchymal stem cells after iron labeling with iron sucrose. Stem Cells and Development, 23(21), 2568-2580. https://doi.org/10.1089/scd. 2014.0153

69. Papadimitriou, N., Li, S., \& Barreto Henriksson, H. (2015). Iron sucrose-labeled human mesenchymal stem cells: In vitro multilineage capability and in vivo traceability in a lapine xenotransplantation model. Stem Cells and Development, 24(20), 24032412. https://doi.org/10.1089/scd.2015.0140

70. Henriksson, H. B., Papadimitriou, N., Hingert, D., Baranto, A., Lindahl, A., \& Brisby, H. (2019). The traceability of mesenchymal stromal cells after injection into degenerated discs in patients with Low Back pain. Stem Cells and Development, 28(17), 12031211. https://doi.org/10.1089/scd.2019.0074

71. Kerans, F. F. A., Lungaro, L., Azfer, A., \& Salter, D. M. (2018). The potential of intrinsically magnetic mesenchymal stem cells for tissue engineering. International Journal of Molecular Sciences, 19(10). https://doi.org/10.3390/ijms19103159

72. Altanerova, U., Babincova, M., Babinec, P., Benejova, K., Jakubechova, J., Altanerova, V., ... Altaner, C. (2017). Human mesenchymal stem cell-derived iron oxide exosomes allow targeted ablation of tumor cells via magnetic hyperthermia. International Journal of Nanomedicine, 12, 7923-7936. https://doi. org/10.2147/IJN.S145096

73. Castaneda, R. T., Khurana, A., Khan, R., \& Daldrup-Link, H. E. (2011). Labeling stem cells with ferumoxytol, an FDA-approved iron oxide nanoparticle. Journal of Visualized Experiments: JoVE, 57, e3482. https://doi.org/10.3791/3482

74. Liu, L., Tseng, L., Ye, Q., Wu, Y. L., Bain, D. J., \& Ho, C. (2016). A new method for preparing mesenchymal stem cells and labeling with Ferumoxytol for cell tracking by MRI. Scientific Reports, 6, 26271. https://doi.org/10.1038/srep26271

75. Khurana, A., Chapelin, F., Beck, G., Lenkov, O. D., Donig, J., Nejadnik, H., ... Daldrup-Link, H. E. (2013). Iron administration before stem cell harvest enables MR imaging tracking after transplantation. Radiology, 269(1), 186-197. https://doi.org/10. 1148/radiol.13130858

76. Liu, L., \& Ho, C. (2017). Mesenchymal stem cell preparation and transfection-free Ferumoxytol labeling for MRI cell tracking. 
Current Protocols in Stem Cell Biology, 43, 2B.7.1-2B.7.14. https://doi.org/10.1002/cpsc.38

77. Hour, F. Q., Moghadam, A. J., Shakeri-Zadeh, A., Bakhtiyari, M., Shabani, R., \& Mehdizadeh, M. (2020). Magnetic targeted delivery of the SPIONs-labeled mesenchymal stem cells derived from human Wharton's jelly in Alzheimer's rat models. Journal of Controlled Release: Official Journal of the Controlled Release Society, 321, 430-441. https://doi.org/10.1016/j.jconrel.2020.02. 035

78. Hamilton, A. M., Cheung, W.-Y., Gómez-Aristizábal, A., Sharma, A., Nakamura, S., Chaboureau, A., ... Viswanathan, S. (2019). Iron nanoparticle-labeled murine mesenchymal stromal cells in an osteoarthritic model persists and suggests anti-inflammatory mechanism of action. PLoS One, 14(12), e0214107. https://doi. org/10.1371/journal.pone.0214107

79. Nejadnik, H., Pandit, P., Lenkov, O., Lahiji, A. P., Yerneni, K., \& Daldrup-Link, H. (2019). Ferumoxytol can be used for quantitative magnetic particle imaging of transplanted stem cells. Molecular imaging and biology : MIB : the official publication of the Academy of Molecular Imaging, 21(3), 465-472. https:// doi.org/10.1007/s11307-018-1276-X

80. Lee, N. K., Kim, H. S., Yoo, D., Hwang, J. W., Choi, S. J., Oh, W., ... Na, D. L. (2017). Magnetic resonance imaging of Ferumoxytol-labeled human mesenchymal stem cells in the mouse brain. Stem Cell Reviews, 13(1), 127-138. https://doi.org/10. 1007/s12015-016-9694-0

81. Elhalawani, H., Awan, M. J., Ding, Y., Mohamed, A. S. R., Elsayes, A. K., Abu-Gheida, I., ... Fuller, C. D. (2020). Data from a terminated study on iron oxide nanoparticle magnetic resonance imaging for head and neck tumors. Scientific Data, 7(1), 63. https://doi.org/10.1038/s41597-020-0392-z

82. Mehta, K. J., Ahmed, B. Y., \& Farnaud, S. J. (2019). A novel human neuronal cell model to study Iron accumulation in Parkinson's disease, 9(1), 461. https://doi.org/10.4172/2161-0460. 1000461

83. Wood, H. (2020). Brain iron correlates with cognitive change in Parkinson disease. Nature Reviews Neurology, 16(4), 184-184. https://doi.org/10.1038/s41582-020-0339-1

84. Mehta, K. J., Farnaud, S. J., \& Sharp, P. A. (2019). Iron and liver fibrosis: Mechanistic and clinical aspects. World Journal of Gastroenterology, 25(5), 521-538. https://doi.org/10.3748/wjg. v25.i5.521

85. Khalifa, Y. H., Mourad, G. M., Stephanos, W. M., Omar, S. A., \& Mehanna, R. A. (2019). Bone marrow-derived mesenchymal stem cell potential regression of dysplasia associating experimental liver fibrosis in albino rats. BioMed Research International, 2019, 5376165. https://doi.org/10.1155/2019/5376165

86. Ghanem, L. Y., Mansour, I. M., Abulata, N., Akl, M. M., Demerdash, Z. A., El Baz, H. G., ... Hassan, A. S. M. (2019). Liver macrophage depletion ameliorates the effect of mesenchymal stem cell transplantation in a murine model of injured liver. Scientific Reports, 9(1), 35. https://doi.org/10.1038/ s41598-018-37184-4

87. Faidah, M., Noorwali, A., Atta, H., Ahmed, N., Habib, H., Damiati, L., ... Khabaz, M. N. (2017). Mesenchymal stem cell therapy of hepatocellular carcinoma in rats: Detection of cell homing and tumor mass by magnetic resonance imaging using iron oxide nanoparticles. Advances in Clinical and Experimental Medicine: Official Organ Wroclaw Medical University, 26(8), 1171-1178. https://doi.org/10.17219/acem/67563

88. Mathiasen, A. B., Qayyum, A. A., Jørgensen, E., Helqvist, S., Ekblond, A., Ng, M., ... Kastrup, J. (2019). In vivo MRI tracking of mesenchymal stromal cells labeled with Ultrasmall paramagnetic Iron oxide particles after Intramyocardial transplantation in patients with chronic ischemic heart disease. Stem Cells International, 2019, 2754927. https://doi.org/10.1155/2019/2754927
89. Anselmo, A. C., \& Mitragotri, S. (2019). Nanoparticles in the clinic: An update. Bioengineering \& Translational Medicine, 4(3). https://doi.org/10.1002/btm2.10143

90. Derfoul, A., Miyoshi, A. D., Freeman, D. E., \& Tuan, R. S. (2007). Glucosamine promotes chondrogenic phenotype in both chondrocytes and mesenchymal stem cells and inhibits MMP-13 expression and matrix degradation. Osteoarthritis and Cartilage, 15(6), 646-655. https://doi.org/10.1016/j.joca.2007.01.014

91. Guldris, N., Argibay, B., Gallo, J., Iglesias-Rey, R., Carbó-Argibay, E., Kolen'ko, Y. V., ... Rivas, J. (2017). Magnetite nanoparticles for stem cell labeling with high efficiency and longterm in vivo tracking. Bioconjugate Chemistry, 28(2), 362-370. https://doi.org/10.1021/acs.bioconjchem.6b00522

92. Qiao, Y., Gumin, J., MacLellan, C. J., Gao, F., Bouchard, R., Lang, F. F., ... Melancon, M. P. (2018). Magnetic resonance and photoacoustic imaging of brain tumor mediated by mesenchymal stem cell labeled with multifunctional nanoparticle introduced via carotid artery injection. Nanotechnology, 29(16), 165101. https://doi.org/10.1088/1361-6528/aaaf16

93. Kim, T., Lemaster, J. E., Chen, F., Li, J., \& Jokerst, J. V. (2017). Photoacoustic imaging of human mesenchymal stem cells labeled with Prussian blue-poly(l-lysine) Nanocomplexes. ACS Nano, 11(9), 9022-9032. https://doi.org/10.1021/acsnano.7b03519

94. Mishra, S. K., Khushu, S., Singh, A. K., \& Gangenahalli, G. (2018). Homing and tracking of Iron oxide labelled mesenchymal stem cells after infusion in traumatic brain injury mice: A longitudinal in vivo MRI study. Stem Cell Reviews and Reports, 14(6), 888-900. https://doi.org/10.1007/s12015-018-9828-7

95. He, H., Ye, J., Liu, E., Liang, Q., Liu, Q., \& Yang, V. C. (2014). Low molecular weight protamine (LMWP): A nontoxic protamine substitute and an effective cell-penetrating peptide. Journal of Controlled Release: Official Journal of the Controlled Release Society, 193, 63-73. https://doi.org/10.1016/j.jconrel.2014.05. 056

96. Suh, J. S., Lee, J. Y., Choi, Y. S., Yu, F., Yang, V., Lee, S. J., ... Park, Y. J. (2009). Efficient labeling of mesenchymal stem cells using cell permeable magnetic nanoparticles. Biochemical and Biophysical Research Communications, 379(3), 669-675. https:// doi.org/10.1016/j.bbrc.2008.12.041

97. Xu, C., Miranda-Nieves, D., Ankrum, J. A., Matthiesen, M. E., Phillips, J. A., Roes, I., ... Karp, J. M. (2012). Tracking mesenchymal stem cells with Iron oxide nanoparticle loaded poly(lactide-co-glycolide) microparticles. Nano Letters, 12(8), 4131-4139. https://doi.org/10.1021/nl301658q

98. Zhao, Y.-Z., Chen, R., Xue, P.-P., Luo, L.-Z., Zhong, B., Tong, M.-Q., ... Xu, H.-L. (2021). Magnetic PLGA microspheres loaded with SPIONs promoted the reconstruction of bone defects through regulating the bone mesenchymal stem cells under an external magnetic field. Materials Science and Engineering: $C$, 122, 111877. https://doi.org/10.1016/j.msec.2021.111877

99. Schmidtke-Schrezenmeier, G., Urban, M., Musyanovych, A., Mailänder, V., Rojewski, M., Fekete, N., ... Schrezenmeier, H. (2011). Labeling of mesenchymal stromal cells with iron oxidepoly(l-lactide) nanoparticles for magnetic resonance imaging: Uptake, persistence, effects on cellular function and magnetic resonance imaging properties. Cytotherapy, 13(8), 962-975. https://doi.org/10.3109/14653249.2011.571246

100. Duan, L., Zuo, J., Zhang, F., Li, B., Xu, Z., Zhang, H., ... Jiang, J. (2020). Magnetic targeting of HU-MSCs in the treatment of glucocorticoid-associated osteonecrosis of the femoral head through Akt/Bcl2/bad/Caspase-3 pathway. International Journal of Nanomedicine, 15, 3605-3620. https://doi.org/10.2147/ IJN.S244453

101. Liu, Y., Liu, Y., Zheng, C., Huang, N., Chen, X., Zhu, X., ... Liu, J. (2018). Ru nanoparticles coated with $\gamma-\mathrm{Fe} 2 \mathrm{O} 3$ promoting and monitoring the differentiation of human mesenchymal stem cells 
via MRI tracking. Colloids and surfaces, B, Biointerfaces, 170, 701-711. https://doi.org/10.1016/j.colsurfb.2018.05.041

102. Mehta, K. J., Coombes, J. D., Briones-Orta, M., Manka, P. P., Williams, R., Patel, V. B., \& Syn, W.-K. (2018). Iron enhances hepatic Fibrogenesis and activates transforming growth factor- $\beta$ signaling in murine hepatic stellate cells. The American Journal of the Medical Sciences, 355(2), 183-190. https://doi.org/10. 1016/j.amjms.2017.08.012

103. Im, G.-B., Kim, Y. H., Kim, Y.-J., Kim, S.-W., Jung, E., Jeong, G.-J., ... Bhang, S. H. (2019). Enhancing the wound healing effect of conditioned medium collected from mesenchymal stem cells with high passage number using bioreducible nanoparticles. International Journal of Molecular Sciences, 20(19). https://doi. org/10.3390/ijms20194835

104. Kim, Y.-J., Lee, J., Im, G.-B., Song, J., Song, J., Chung, J., ... Bhang, S. H. (2021). Dual ion releasing nanoparticles for modulating osteogenic cellular microenvironment of human mesenchymal stem cells, Materials (Basel, Switzerland), 14(2). https:// doi.org/10.3390/ma14020412

105. Zhang, C., Liu, Z., Zhang, Y., Ma, L., Song, E., \& Song, Y. (2020). "Iron free" zinc oxide nanoparticles with ion-leaking properties disrupt intracellular ROS and iron homeostasis to induce ferroptosis. Cell Death \& Disease, 11(3), 183. https:// doi.org/10.1038/s41419-020-2384-5

106. Liu, H.-M., Wu, S.-H., Lu, C.-W., Yao, M., Hsiao, J.-K., Hung, Y., ... Chen, Y.-C. (2008). Mesoporous silica nanoparticles improve magnetic labeling efficiency in human stem cells. Small (Weinheim an Der Bergstrasse, Germany), 4(5), 619-626. https://doi.org/10.1002/smll.200700493

107. Wang, H., Wang, Y. J., Leung, K. C., Sheng, H., Zhang, G., Lee, S. K. M., ... Griffith, J. F. (2008). Mesenchymal stem cell intracellular labeling using silica-coated superparamagnetic iron oxide nanoparticles with amine functional peripheries. In 2008 international conference on information technology and applications in biomedicine (pp. 187-189). https://doi.org/10.1109/ ITAB.2008.4570593

108. Yao, D., Liu, N.-N., \& Mo, B.-W. (2020). Assessment of proliferation, migration and differentiation potentials of bone marrow mesenchymal stem cells labeling with silica-coated and amine-modified superparamagnetic iron oxide nanoparticles. Cytotechnology, 72(4), 513-525. https://doi.org/10.1007/ s10616-020-00397-5

109. Novotna, B., Jendelova, P., Kapcalova, M., Rossner, P., Turnovcova, K., Bagryantseva, Y., ... Sykova, E. (2012). Oxidative damage to biological macromolecules in human bone marrow mesenchymal stromal cells labeled with various types of iron oxide nanoparticles. Toxicology Letters, 210(1), 53-63. https:// doi.org/10.1016/j.toxlet.2012.01.008

110. Novotna, B., Herynek, V., Rossner, P., Turnovcova, K., \& Jendelova, P. (2017). The effects of grafted mesenchymal stem cells labeled with iron oxide or cobalt-zinc-iron nanoparticles on the biological macromolecules of rat brain tissue extracts. International Journal of Nanomedicine, 12, 4519-4526. https://doi.org/ 10.2147/IJN.S133156

111. Hsu, F.-T., Wei, Z.-H., Hsuan, Y. C.-Y., Lin, W., Su, Y.-C., Liao, C.-H., \& Hsieh, C.-L. (2018). MRI tracking of polyethylene glycol-coated superparamagnetic iron oxide-labelled placentaderived mesenchymal stem cells toward glioblastoma stem-like cells in a mouse model. Artificial Cells, Nanomedicine, and Biotechnology, 46(sup3), S448-S459. https://doi.org/10.1080/21691 401.2018.1499661

112. Naseroleslami, M., Aboutaleb, N., \& Mokhtari, B. (2021). Amniotic membrane mesenchymal stem cells labeled by iron oxide nanoparticles exert cardioprotective effects against isoproterenol (ISO)-induced myocardial damage by targeting inflammatory MAPK/NF-кB pathway. Drug Delivery and Translational Research, 11(1), 242-254. https://doi.org/10.1007/ s13346-020-00788-3

113. Mathieu, P., Coppel, Y., Respaud, M., Nguyen, Q. T., Boutry, S., Laurent, S., ... Amiens, C. (2019). Silica coated Iron/Iron oxide nanoparticles as a Nano-platform for T2 weighted magnetic resonance imaging. Molecules, 24(24). https://doi.org/10.3390/molec ules24244629

114. Detante, O., Valable, S., de Fraipont, F., Grillon, E., Barbier, E. L., Moisan, A., ... Richard, M.-J. (2012). Magnetic resonance imaging and fluorescence labeling of clinical-grade mesenchymal stem cells without impacting their phenotype: Study in a rat model of stroke. Stem Cells Translational Medicine, 1(4), 333-340. https://doi.org/10.5966/sctm.2011-0043

115. Kim, T. H., Kim, J. K., Shim, W., Kim, S. Y., Park, T. J., \& Jung, J. Y. (2010). Tracking of transplanted mesenchymal stem cells labeled with fluorescent magnetic nanoparticle in liver cirrhosis rat model with 3-T MRI. Magnetic Resonance Imaging, 28(7), 1004-1013. https://doi.org/10.1016/j.mri.2010.03.047

116. Addicott, B., Willman, M., Rodriguez, J., Padgett, K., Han, D., Berman, D., ... Kenyon, N. S. (2011). Mesenchymal stem cell labeling and in vitro MR characterization at $1.5 \mathrm{~T}$ of new SPIO contrast agent: Molday ION rhodamine-B ${ }^{\mathrm{TM}}$. Contrast Media \& Molecular Imaging, 6(1), 7-18. https://doi.org/10.1002/cmmi. 396

117. Andrzejewska, A., Jablonska, A., Seta, M., Dabrowska, S., Walczak, P., Janowski, M., \& Lukomska, B. (2019). Labeling of human mesenchymal stem cells with different classes of vital stains: Robustness and toxicity. Stem Cell Research \& Therapy, 10(1), 187. https://doi.org/10.1186/s13287-019-1296-8

118. Cai, J., Zhang, X., Wang, X., Li, C., \& Liu, G. (2008). In vivo MR imaging of magnetically labeled mesenchymal stem cells transplanted into rat liver through hepatic arterial injection. Contrast Media \& Molecular Imaging, 3(2), 61-66. https://doi.org/ $10.1002 / \mathrm{cmmi} .231$

119. Kubelick, K. P., \& Emelianov, S. Y. (2020). Prussian blue nanocubes as a multimodal contrast agent for image-guided stem cell therapy of the spinal cord. Photoacoustics, 18, 100166. https:// doi.org/10.1016/j.pacs.2020.100166

120. Dumani, D. S., Cook, J. R., Kubelick, K. P., Luci, J. J., \& Emelianov, S. Y. (2020). Photomagnetic Prussian blue nanocubes: Synthesis, characterization, and biomedical applications. Nanomedicine: Nanotechnology, Biology, and Medicine, 24, 102138. https://doi.org/10.1016/j.nano.2019.102138

121. Magro, M., Martinello, T., Bonaiuto, E., Gomiero, C., Baratella, D., Zoppellaro, G., ... Vianello, F. (2017). Covalently bound DNA on naked iron oxide nanoparticles: Intelligent colloidal nano-vector for cell transfection. Biochimica et Biophysica Acta. General Subjects, 1861(11 Pt a), 2802-2810. https://doi.org/10. 1016/j.bbagen.2017.07.025

122. Xie, L., Tong, W., Yu, D., Xu, J., Li, J., \& Gao, C. (2012). Bovine serum albumin nanoparticles modified with multilayers and aptamers for $\mathrm{pH}-$ responsive and targeted anti-cancer drug delivery. Journal of Materials Chemistry, 22(13), 6053-6060. https://doi.org/10.1039/C2JM16831F

123. Jiang, P., Zhang, Y., Zhu, C., Zhang, W., Mao, Z., \& Gao, C. (2016). Fe3O4/BSA particles induce osteogenic differentiation of mesenchymal stem cells under static magnetic field. Acta Biomaterialia, 46, 141-150. https://doi.org/10.1016/j.actbio.2016. 09.020

124. Xu, C., Feng, Q., Yang, H., Wang, G., Huang, L., Bai, Q., ... Cheng, Y. (2018). A light-triggered mesenchymal stem cell delivery system for photoacoustic imaging and chemo-Photothermal therapy of triple negative breast Cancer. Advanced Science 
(Weinheim, Baden-Wurttemberg, Germany), 5(10), 1800382. https://doi.org/10.1002/advs.201800382

125. Liu, Y., Zhao, J., Jiang, J., Chen, F., \& Fang, X. (2020). Doxorubicin delivered using nanoparticles camouflaged with mesenchymal stem cell membranes to treat Colon Cancer. International Journal of Nanomedicine, 15, 2873-2884. https://doi.org/10. 2147/IJN.S242787

126. Arbab, A. S., Yocum, G. T., Wilson, L. B., Parwana, A., Jordan, E. K., Kalish, H., \& Frank, J. A. (2004). Comparison of transfection agents in forming complexes with ferumoxides, cell labeling efficiency, and cellular viability. Molecular Imaging, 3(1), 24-32. https://doi.org/10.1162/153535004773861697

127. Hang, D., Li, F., Che, W., Wu, X., Wan, Y., Wang, J., \& Zheng, Y. (2017). One-stage positron emission tomography and magnetic resonance imaging to assess mesenchymal stem cell survival in a canine model of intervertebral disc degeneration. Stem Cells and Development, 26(18), 1334-1343. https://doi.org/10. 1089/scd.2017.0103

128. Nejadnik, H., Taghavi-Garmestani, S.-M., Madsen, S. J., Li, K., Zanganeh, S., Yang, P., ... Daldrup-Link, H. E. (2018). The protein Corona around nanoparticles facilitates stem cell labeling for clinical MR imaging. Radiology, 286(3), 938-947. https://doi.org/10.1148/radiol.2017170130

129. Ventola, C. L. (2017). Progress in nanomedicine: Approved and investigational Nanodrugs. Pharmacy and Therapeutics, 42(12), 742-755 Retrieved from https://www.ncbi.nlm.nih. gov/pmc/articles/PMC5720487/

130. Schäfer, R., Kehlbach, R., Müller, M., Bantleon, R., Kluba, T., Ayturan, M., ... Wiskirchen, J. (2009). Labeling of human mesenchymal stromal cells with superparamagnetic iron oxide leads to a decrease in migration capacity and colony formation ability. Cytotherapy, 11(1), 68-78. https://doi.org/10.1080/ 14653240802666043

131. Lu, Y., Wei, L., Zhang, X., Cai, J., Zhu, Y., Xiao, J., ... Li, S. (2018). The regulation of mesenchymal stem cell therapy through magnetic resonance imaging agents-based cellular condition and oxygen environment. Journal of Biomedical Nanotechnology, 14(11), 1906-1920. https://doi.org/10.1166/ jbn.2018.2639

132. Xu, Q., Zhang, T., Wang, Q., Jiang, X., Li, A., Li, Y., ... Gao, J. (2018). Uniformly sized iron oxide nanoparticles for efficient gene delivery to mesenchymal stem cells. International Journal of Pharmaceutics, 552(1-2), 443-452. https://doi.org/10.1016/j. ijpharm.2018.10.023

133. Silva, L. H. A., Cruz, F. F., Morales, M. M., Weiss, D. J., \& Rocco, P. R. M. (2017). Magnetic targeting as a strategy to enhance therapeutic effects of mesenchymal stromal cells. Stem Cell Research \& Therapy, 8(1), 58. https://doi.org/10.1186/ s13287-017-0523-4

134. Ohki, A., Saito, S., \& Fukuchi, K. (2020). Magnetic resonance imaging of umbilical cord stem cells labeled with superparamagnetic iron oxide nanoparticles: Effects of labelling and transplantation parameters. Scientific Reports, 10(1), 13684. https://doi. org/10.1038/s41598-020-70291-9

135. Lee, E. S. M., Chan, J., Shuter, B., Tan, L. G., Chong, M. S. K., Ramachandra, D. L., ... Wang, S.-C. (2009). Microgel iron oxide nanoparticles for tracking human fetal mesenchymal stem cells through magnetic resonance imaging. Stem Cells (Dayton, Ohio), 27(8), 1921-1931. https://doi.org/10.1002/stem.112

136. Strioga, M., Viswanathan, S., Darinskas, A., Slaby, O., \& Michalek, J. (2012). Same or not the same? Comparison of adipose tissue-derived versus bone marrow-derived mesenchymal stem and stromal cells. Stem Cells and Development, 21(14), 2724-2752. https://doi.org/10.1089/scd.2011.0722

137. Im, G.-I., Shin, Y.-W., \& Lee, K.-B. (2005). Do adipose tissuederived mesenchymal stem cells have the same osteogenic and chondrogenic potential as bone marrow-derived cells? Osteoarthritis and Cartilage, 13(10), 845-853. https://doi.org/10.1016/j. joca.2005.05.005

138. Mohamed-Ahmed, S., Fristad, I., Lie, S. A., Suliman, S. Mustafa, K., Vindenes, H., \& Idris, S. B. (2018). Adiposederived and bone marrow mesenchymal stem cells: A donormatched comparison. Stem Cell Research \& Therapy, 9(1), 168. https://doi.org/10.1186/s13287-018-0914-1

139. Burrow, K. L., Hoyland, J. A., \& Richardson, S. M. (2017). Human adipose-derived stem cells exhibit enhanced proliferative capacity and retain multipotency longer than donor-matched bone marrow mesenchymal stem cells during expansion in vitro. Stem Cells International, 2017, e2541275. https://doi.org/10. $1155 / 2017 / 2541275$

140. Mohamed-Ahmed, S., Yassin, M. A., Rashad, A., Espedal, H., Idris, S. B., Finne-Wistrand, A., ... Fristad, I. (2021). Comparison of bone regenerative capacity of donor-matched human adipose-derived and bone marrow mesenchymal stem cells. Cell and Tissue Research, 383(3), 1061-1075. https://doi.org/10. 1007/s00441-020-03315-5

141. Stanko, P., Kaiserova, K., Altanerova, V., \& Altaner, C. (2014). Comparison of human mesenchymal stem cells derived from dental pulp, bone marrow, adipose tissue, and umbilical cord tissue by gene expression. Biomedical Papers of the Medical Faculty of the University Palacky, Olomouc, Czechoslovakia, 158(3), 373-377. https://doi.org/10.5507/bp.2013.078

142. Au, P., Tam, J., Fukumura, D., \& Jain, R. K. (2008). Bone marrow-derived mesenchymal stem cells facilitate engineering of long-lasting functional vasculature. Blood, 111(9), 4551-4558. https://doi.org/10.1182/blood-2007-10-118273

143. Zhao, L.-R., Duan, W.-M., Reyes, M., Keene, C. D., Verfaillie, C. M., \& Low, W. C. (2002). Human bone marrow stem cells exhibit neural phenotypes and ameliorate neurological deficits after grafting into the ischemic brain of rats. Experimental Neurology, 174(1), 11-20. https://doi.org/10.1006/exnr.2001.7853

144. Altanerova, V., Cihova, M., Babic, M., Rychly, B., Ondicova, K., Mravec, B., \& Altaner, C. (2012). Human adipose tissue-derived mesenchymal stem cells expressing yeast cytosinedeaminase::Uracil phosphoribosyltransferase inhibit intracerebral rat glioblastoma. International Journal of Cancer, 130(10), 2455-2463. https://doi.org/10.1002/ijc.26278

145. Fan, J., Tan, Y., Jie, L., Wu, X., Yu, R., \& Zhang, M. (2013). Biological activity and magnetic resonance imaging of superparamagnetic iron oxide nanoparticles-labeled adipose-derived stem cells. Stem Cell Research \& Therapy, 4(2), 44. https://doi. org/10.1186/scrt191

146. Labusca, L., Herea, D.-D., Emanuela Minuti, A., Stavila, C., Danceanu, C., Plamadeala, P., ... Lupu, N. (2021). Magnetic nanoparticles and magnetic field exposure enhances Chondrogenesis of human adipose derived mesenchymal stem cells but not of Wharton jelly mesenchymal stem cells. Frontiers in Bioengineering and Biotechnology, 9, 875. https://doi.org/10.3389/ fbioe.2021.737132

147. Baron, F., Lechanteur, C., Willems, E., Bruck, F., Baudoux, E., Seidel, L., ... Beguin, Y. (2010). Cotransplantation of mesenchymal stem cells might prevent death from graft-versus-host disease (GVHD) without abrogating graft-versus-tumor effects after HLA-mismatched allogeneic transplantation following nonmyeloablative conditioning. Biology of Blood and Marrow Transplantation: Journal of the American Society for Blood and Marrow Transplantation, 16(6), 838-847. https://doi.org/10. 1016/j.bbmt.2010.01.011

148. Introna, M., Lucchini, G., Dander, E., Galimberti, S., Rovelli, A., Balduzzi, A., ... Biagi, E. (2014). Treatment of graft versus host disease with mesenchymal stromal cells: A phase I study on 40 adult and pediatric patients. Biology of Blood and Marrow 
Transplantation: Journal of the American Society for Blood and Marrow Transplantation, 20(3), 375-381. https://doi.org/10. 1016/j.bbmt.2013.11.033

149. Pérez-Simon, J. A., López-Villar, O., Andreu, E. J., Rifón, J., Muntion, S., Diez Campelo, M., ... Cañizo, C. D. (2011). Mesenchymal stem cells expanded in vitro with human serum for the treatment of acute and chronic graft-versus-host disease: Results of a phase I/II clinical trial. Haematologica, 96(7), 1072-1076. https://doi.org/10.3324/haematol.2010.038356

150. Emadedin, M., Ghorbani Liastani, M., Fazeli, R., Mohseni, F., Moghadasali, R., Mardpour, S., ... Aghdami, N. (2015). Longterm follow-up of intra-articular injection of autologous mesenchymal stem cells in patients with knee, ankle, or hip osteoarthritis. Archives of Iranian Medicine, 18(6), 336-344 015186/ AIM.003.

151. Jo, C. H., Lee, Y. G., Shin, W. H., Kim, H., Chai, J. W., Jeong, E. C., ... Yoon, K. S. (2014). Intra-articular injection of mesenchymal stem cells for the treatment of osteoarthritis of the knee: A proof-of-concept clinical trial. Stem Cells (Dayton, Ohio), 32(5), 1254-1266. https://doi.org/10.1002/stem.1634

152. Orozco, L., Munar, A., Soler, R., Alberca, M., Soler, F., Huguet, M., ... García-Sancho, J. (2014). Treatment of knee osteoarthritis with autologous mesenchymal stem cells: Two-year follow-up results. Transplantation, 97(11), e66-e68. https://doi.org/10. 1097/TP.0000000000000167

153. Connick, P., Kolappan, M., Patani, R., Scott, M. A., Crawley, C., He, X.-L., ... Chandran, S. (2011). The mesenchymal stem cells in multiple sclerosis (MSCIMS) trial protocol and baseline cohort characteristics: An open-label pre-test: Post-test study with blinded outcome assessments. Trials, 12, 62. https://doi. org/10.1186/1745-6215-12-62

154. Chang, Y. S., Ahn, S. Y., Yoo, H. S., Sung, S. I., Choi, S. J., Oh, W. I., \& Park, W. S. (2014). Mesenchymal stem cells for bronchopulmonary dysplasia: phase 1 dose-escalation clinical trial. The Journal of Pediatrics, 164(5), 966-972.e6. https://doi.org/ 10.1016/j.jpeds.2013.12.011

155. Weiss, D. J., Casaburi, R., Flannery, R., LeRoux-Williams, M., \& Tashkin, D. P. (2013). A placebo-controlled, randomized trial of mesenchymal stem cells in COPD. Chest, 143(6), 1590-1598. https://doi.org/10.1378/chest.12-2094

156. Wilson, J. G., Liu, K. D., Zhuo, H., Caballero, L., McMillan, M., Fang, X., ... Matthay, M. A. (2015). Mesenchymal stem (stromal) cells for treatment of ARDS: A phase 1 clinical trial. The Lancet. Respiratory Medicine, 3(1), 24-32. https://doi.org/ 10.1016/S2213-2600(14)70291-7

157. Forbes, G. M., Sturm, M. J., Leong, R. W., Sparrow, M. P., Segarajasingam, D., Cummins, A. G., ... Herrmann, R. P. (2014). A phase 2 study of allogeneic mesenchymal stromal cells for luminal Crohn's disease refractory to biologic therapy. Clinical Gastroenterology and Hepatology: The Official Clinical Practice Journal of the American Gastroenterological Association, 12(1), 64-71. https://doi.org/10.1016/j.cgh.2013.06.021

158. Molendijk, I., Bonsing, B. A., Roelofs, H., Peeters, K. C. M. J., Wasser, M. N. J. M., Dijkstra, G., ... Hommes, D. W. (2015). Allogeneic bone marrow-derived mesenchymal stromal cells promote healing of refractory perianal fistulas in patients with Crohn's disease. Gastroenterology, 149(4), 918-927.e6. https:// doi.org/10.1053/j.gastro.2015.06.014

159. Musialek, P., Mazurek, A., Jarocha, D., Tekieli, L., Szot, W., Kostkiewicz, M., ... Majka, M. (2015). Myocardial regeneration strategy using Wharton's jelly mesenchymal stem cells as an offthe-shelf "unlimited" therapeutic agent: Results from the acute myocardial infarction first-in-man study. Postepy W Kardiologii Interwencyjnej = Advances in Interventional Cardiology, 11(2), 100-107. https://doi.org/10.5114/pwki.2015.52282
160. Valenti, M. T., Serena, M., Carbonare, L. D., \& Zipeto, D. (2019). CRISPR/Cas system: An emerging technology in stem cell research. World Journal of Stem Cells, 11(11), 937-956. https://doi.org/10.4252/wjsc.v11.i11.937

161. Hassanzadeh, A., Altajer, A. H., Rahman, H. S., Saleh, M. M., Bokov, D. O., Abdelbasset, W. K., ... Jarahian, M. (2021). Mesenchymal Stem/Stromal Cell-Based Delivery: A Rapidly Evolving Strategy for Cancer Therapy. Frontiers in Cell and Developmental Biology, 9, 686453. https://doi.org/10.3389/fcell.2021. 686453

162. Babajani, A., Soltani, P., Jamshidi, E., Farjoo, M. H., \& Niknejad, H. (2020). Recent Advances on Drug-Loaded Mesenchymal Stem Cells With Anti-neoplastic Agents for Targeted Treatment of Cancer. Frontiers in Bioengineering and Biotechnology, 8. https://doi.org/10.3389/fbioe.2020.00748

163. Gjorgieva, D., Zaidman, N., \& Bosnakovski, D. (2013). Mesenchymal stem cells for anti-cancer drug delivery. Recent Patents on Anti-Cancer Drug Discovery, 8(3), 310-318. https://doi.org/ $10.2174 / 15748928113089990040$

164. Takayama, Y., Kusamori, K., \& Nishikawa, M. (2021). Mesenchymal stem/stromal cells as next-generation drug delivery vehicles for cancer therapeutics. Expert Opinion on Drug Delivery, 18(11), 1627-1642. https://doi.org/10.1080/17425247.2021. 1960309

165. Krueger, T. E. G., Thorek, D. L. J., Denmeade, S. R., Isaacs, J. T., \& Brennen, W. N. (2018). Concise review: Mesenchymal stem cell-based drug delivery: The good, the bad, the ugly, and the promise. Stem Cells Translational Medicine, 7(9), 651-663. https://doi.org/10.1002/sctm.18-0024

166. Wang, X., Chen, H., Zeng, X., Guo, W., Jin, Y., Wang, S., ... Mei, L. (2019). Efficient lung cancer-targeted drug delivery via a nanoparticle/MSC system. Acta Pharmaceutica Sinica B, 9(1), 167-176. https://doi.org/10.1016/j.apsb.2018.08.006

167. Iafrate, M., \& Fruhwirth, G. O. (2020). How non-invasive in vivo cell tracking supports the development and translation of Cancer immunotherapies. Frontiers in Physiology, 11. https://doi.org/10. 3389/fphys.2020.00154

168. Rajendran, R. L., Jogalekar, M. P., Gangadaran, P., \& Ahn, B.-C. (2020). Noninvasive in vivo cell tracking using molecular imaging: A useful tool for developing mesenchymal stem cell-based cancer treatment. World Journal of Stem Cells, 12(12), 14921510. https://doi.org/10.4252/wjsc.v12.i12.1492

169. Jokerst, J. V., Thangaraj, M., Kempen, P. J., Sinclair, R., \& Gambhir, S. S. (2012). Photoacoustic imaging of mesenchymal stem cells in living mice via silica-coated gold Nanorods. ACS Nano, 6(7), 5920-5930. https://doi.org/10.1021/nn302042y

170. Gildehaus, F. J., Haasters, F., Drosse, I., Wagner, E., Zach, C., Mutschler, W., ... Schieker, M. (2011). Impact of Indium-111 Oxine labelling on viability of human mesenchymal stem cells in vitro, and 3D cell-tracking using SPECT/CT in vivo. Molecular Imaging and Biology, 13(6), 1204-1214. https://doi.org/10. 1007/s11307-010-0439-1

171. Wang, F., Dennis, J. E., Awadallah, A., Solchaga, L. A., Molter, J., Kuang, Y., ... Lee, Z. (2009). Transcriptional profiling of human mesenchymal stem cells transduced with reporter genes for imaging. Physiological Genomics, 37(1), 23-34. https://doi. org/10.1152/physiolgenomics.00300.2007

172. Kedziorek, D. A., Muja, N., Walczak, P., Ruiz-Cabello, J., Gilad, A. A., Jie, C. C., \& Bulte, J. W. M. (2010). Gene expression profiling reveals early cellular responses to intracellular magnetic labeling with superparamagnetic iron oxide nanoparticles. Magnetic Resonance in Medicine, 63(4), 1031-1043. https://doi. org/10.1002/mrm.22290

173. Richards, J. M. J., Shaw, C. A., Lang, N. N., Williams, M. C., Semple, S. I. K., MacGillivray, T. J., ... Newby, D. E. (2012). In vivo mononuclear cell tracking using superparamagnetic 
particles of iron oxide: Feasibility and safety in humans. Circulation. Cardiovascular Imaging, 5(4), 509-517. https://doi.org/ 10.1161/CIRCIMAGING.112.972596

174. Kostura, L., Kraitchman, D. L., Mackay, A. M., Pittenger, M. F., \& Bulte, J. W. M. (2004). Feridex labeling of mesenchymal stem cells inhibits chondrogenesis but not adipogenesis or osteogenesis. NMR in Biomedicine, 17(7), 513-517. https://doi.org/10. 1002/nbm. 925

175. Bulte, J. W. M., Kraitchman, D. L., Mackay, A. M., \& Pittenger, M. F. (2004). Chondrogenic differentiation of mesenchymal stem cells is inhibited after magnetic labeling with ferumoxides. Blood, 104(10), 3410-3412; author reply 3412-3413. https://doi. org/10.1182/blood-2004-06-2117

Publisher's Note Springer Nature remains neutral with regard to jurisdictional claims in published maps and institutional affiliations. 